\title{
FinANCIAL INTERMEDIARIES, MARKETS, AND GROWTH
}

by

Falko Fecht, Kevin X.D. Huang, and Antoine Martin

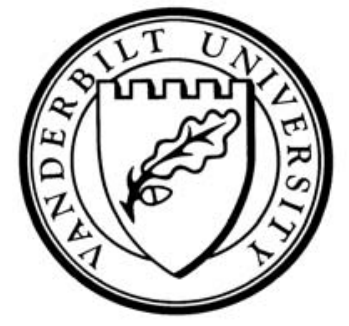

Working Paper No. 07-W14

August 2007

\section{DEPARTMENT OF ECONOMICS \\ VANDERBILT UNIVERSITY \\ NASHVILLE, TN 37235}

www.vanderbilt.edu/econ 


\title{
Financial intermediaries, markets, and growth
}

\author{
Falko Fecht Kevin X.D. Huang Antoine Martin*
}

August 2007

We build a model in which financial intermediaries provide insurance to households against idiosyncratic liquidity shocks. Households can invest in financial markets directly if they pay a cost. In equilibrium, the ability of intermediaries to share risk is constrained by the market. From a growth perspective, this can be beneficial because intermediaries invest less in the productive technology when they provide more risksharing. Our model predicts that bank-oriented economies can grow more slowly than more market-oriented economies, which is consistent with some recent empirical evidence. We show that the mix of intermediaries and markets that maximizes welfare under a given level of financial development depends on economic fundamentals.

Keywords: Financial intermediaries; Financial markets; Risk-sharing; Growth

JEL classification: E44; G10; G20

\footnotetext{
*Fecht: Deutsche Bundesbank (falko.fecht@bundesbank.de). Huang: Department of Economics, Vanderbilt University (kevin.huang@vanderbilt.edu). Martin: Federal Reserve Bank of New York (Antoine.Martin@ny.frb.org). We thank Jerry Hanweck, Paula Hernandez-Verme, Frederick Joutz, Todd Keister, Steve Williamson, as well as seminar participants at University of Missouri, Texas A\&M, UNC Chapel Hill, UC Irvine, UQAM, University of Montreal, Emory University, St. Louis Fed, the BIS, the 2004 Missouri Economic Conference, the 2004 WAFA/FDIC Conference, the 2004 Midwest Macro Meeting, the 2004 Clarence Tow Conference, the 2004 North American Summer Meeting of the Econometric Society, the 2004 Annual Meeting of the Society for Economic Dynamics, the 2004 European Economic Association Meeting, and the 2005 SAET conference for useful comments. All remaining errors are our own. The views expressed here are those of the authors and not necessarily those of the Deutsche Bundesbank, the Federal Reserve Bank of New York, or the Federal Reserve System.
} 


\section{Introduction}

An important question related to both growth and finance theory is whether the financial system influences growth in the long run. We build a model in which financial markets reduce the amount of risk-sharing that financial intermediaries can provide but promote investment in a productive technology. Hence, in our model, marketoriented financial systems yield more growth, but provide less risk-sharing than bankoriented systems. Which system provides the highest welfare is ambiguous.

We build on a model by Fecht (2004) in which banks play two different roles: First, as in Diamond and Dybvig (1983), they provide insurance to consumers against preference shocks. Second, as in Diamond and Rajan (2000, 2001), the refinancing from numerous small depositors enables banks - in contrast to other financial institutions to credibly commit to not renegotiate the repayment obligations on deposits, as this could trigger a run. While banks can invest freely in financial markets, households have to pay a cost to do so. We call households who pay that cost "sophisticated".

As shown in Fecht (2004), a trade-off arises between the amount of risk-sharing provided by banks and the number of sophisticated depositors. Indeed, access to a financial market allows patient sophisticated depositors to renege ex-post on the risksharing arrangement offered by banks. We embed the static model into a dynamic overlapping-generations structure, as in Ennis and Keister (2003). In this dynamic model, there is a trade-off between risk-sharing provided by banks and growth. An increase in risk-sharing implies less investment in productive assets and less growth, because a higher degree of risk-sharing goes along with larger liquidity holdings at any point in time. Because competitive banks must maximize the expected utility of depositors alive at each date, they do not take into account the benefits to future generations of an increase in the capital stock. By constraining the amount of risksharing banks can offer, markets promote investment in capital and thus promote growth. However, since this increase in growth comes at the cost of risk-sharing, the effect of markets on welfare can be positive or negative, depending on parameter values.

While we believe that this trade-off is important, it should be noted that our model 
focuses on the liability side of banks. Thus, because some activities on the asset side of banks may promote growth, our results could overstate the growth reducing impact of bank-oriented systems. ${ }^{1}$ Empirical evidence provided by Beck and Levine (2002) and Levine (2002) suggests that a more developed financial system promotes growth. However, they fail to find any evidence that the composition of the financial system, whether it is bank- or market-based, under a given level of financial development influences growth.

More recent work by Ergungor (forthcoming) can reconcile our results with the data. Ergungor (forthcoming) shows that market-based financial systems promote growth compared with bank-based systems, in countries with flexible legal systems. ${ }^{2}$ The reason is that activities on the asset side of banks have less of a growth-enhancing role in countries with flexible legal systems than in countries with inflexible legal systems. In countries with less flexible legal systems, the asset side of banks probably has a bigger growth-enhancing role, which offsets the effect we describe. In summary, while we believe that the effect we describe is always present, it might be difficult to tease it out of the available data when the asset side of the bank plays an important role in promoting growth. The prediction of our model should be easiest to see in data coming from countries where the asset side of banks plays less of a role in promoting growth, which is what Ergungor's study suggests.

The remainder of the paper proceeds as follows: Section 2 discusses the related literature. Section 3 describes a static model. Section 4 embeds the static model into an OLG framework and reports our main results. Section 5 concludes.

\section{Related literature}

There is a large literature on the nexus between financial systems and economic growth (see Levine 1997 for a review). However, most of this literature is concerned

\footnotetext{
${ }^{1}$ Chakraborty and Ray (2006) emphasize the asset-side of banks.

${ }^{2}$ Countries with flexible legal systems and market-oriented financial systems include the U.S. and the U.K. Those with bank-oriented financial systems include Belgium, Finland, and Norway. The extent to which the financial system is bank-oriented in these countries is comparable to Germany.
} 
with the effect of financial development on the efficiency of investments, i.e., on capital productivity. Only a limited number of papers deal with the impact of financial systems on households' saving decisions - the portfolio choice between liquidity holdings and long-term investments - and their effect on economic growth. For instance, Jappelli and Pagano (1994) show that financial market imperfections may increase the savings rate and thus growth by limiting households' ability to smooth consumption over the life-cycle. Thus, their findings are closely related to our results. But in our model, an increasing efficiency of financial markets restrains banks from providing efficient risk-sharing and thereby increases long-term investment and growth. Levine (1991) studies the effect that the existence of a financial market has on growth in a Diamond-Dybvig setup. He shows that - compared with a situation in which households are autarkic - the possibility of selling long-term financial claims to satisfy liquidity needs increases households willingness to invest in these claims ex-ante, increasing investment and growth. Similarly, Bencivenga and Smith (1991) argue that the introduction of a bank in such an economy has an analogous effect on investment and growth. But these papers do not compare the degree of liquidity insurance provided by the market with those provided by the bank. Neither do they consider the interaction of markets and intermediaries. In our paper, in contrast, we focus on the interaction between financial markets and intermediaries. Intermediaries are shown to promote risk-sharing at the cost of growth, while markets have the opposite effect. Thus, we derive the optimal mix of banks and markets.

Our paper is also related to a literature that compares the performance of markets and intermediaries (see, for example, Antinolfi and Kawamura 2003, Bhattacharya and Padilla 1996, Chakraborty and Ray 2006, Fulghieri and Rovelli 1998, and Qian, John, and John 2004).

The work that is perhaps closest in spirit to our paper is Allen and Gale (1997). They consider an environment in which a financial intermediary can provide risksharing to overlapping generations of households. A financial market constrains the ability of intermediaries to provide risk-sharing. Our model differs from theirs in some important ways. For example, we do not consider intergenerational risk-sharing. However, the results from our static model are similar to theirs. In both models, access 
to a financial market reduces welfare because it limits the risk-sharing banks can provide. Different conclusions arise when we account for the trade-off between risksharing and growth in our dynamic model. Allen and Gale (1997) are unable to study the impact of risk-sharing on growth because their results depend on the assumption that the productive asset is in fixed supply. In contrast, our setup naturally extends to a dynamic case.

This is related to another contribution of our paper. Many models of financial intermediation have the property that markets constrain the amount of risk-sharing intermediaries can offer. This was pointed out by Jacklin (1987) about the Diamond and Dybvig (1983) model. It is also the case in Allen and Gale (1997) and particularly in Diamond (1997). In these models, financial markets lower social welfare because they prevent intermediaries from providing as much risk-sharing as they could. Since markets are assumed to provide no alternative benefit, there is no trade-off. In this paper, in contrast, a meaningful trade-off occurs because markets promote growth. Hence, markets no longer necessarily reduce welfare. ${ }^{3}$

\section{$3 \quad$ A static model}

The environment described in this section is similar to the one in Fecht (2004). The economy takes place at three dates, $t=0,1,2$, and is populated by a mass 1 of households and a large number of banks. There is a unique good in the economy and, at date 0 , households are endowed with 1 unit of this good.

Households learn at date $t=1$ if they are impatient (with probability $q$ ) or patient (with probability $1-q$ ). We assume that the fraction of impatient depositors is also given by $q$. Impatient depositors derive utility from consumption at date 1 , while patient depositors derive utility from consumption at date 2. Expected utility can be

\footnotetext{
${ }^{3}$ Although we focus on growth in this paper, financial markets may provide other benefits that can be traded off against the constraint they impose on intermediaries. For example, markets offer a more diverse set of investment opportunities. Hence, our model may be considered as illustrative of a more fundamental point: Markets and intermediaries provide different benefits, and the optimal mix of those benefits could depend on the parameters of the economy considered.
} 
written as

$$
U\left(c_{1}, c_{2}\right)=q u\left(c_{1}\right)+(1-q) u\left(c_{2}\right) .
$$

The function $u$ exhibits CRRA: $u(c)=\frac{c^{1-\alpha}}{1-\alpha}$, with $\alpha>1$. Whether a household is patient or impatient is private information.

\subsection{Technologies and financial assets}

There are two production technologies in the economy: A storage technology, which returns 1 unit of the good at date $t+1$ for each unit invested at date $t, t=0,1$, and a productive technology, which returns $R$ units of the good at date 2 for each unit invested at date $0 .{ }^{4}$ Anyone can invest in either technology. We think of investing in the productive technology as investing in a project.

Claims on a project can be traded in a secondary market at date 1 . However, not all households are able to distinguish a real project from a fake. Households can become sophisticated, at a cost, or remain unsophisticated. Sophisticated households are able to distinguish real from fake projects while unsophisticated households cannot. Hence, sophisticated households can guarantee a return of $R$ at date 2 on the claims they hold. In contrast, the expected return on a claim held by an unsophisticated household is $\gamma R$ at date 2, where $\gamma$ is the probability that the claim is not fake. We assume $\gamma R<1$.

Households choose whether to become sophisticated at date 0 , and banks cannot observe if a household is sophisticated. To become sophisticated, a household must pay a cost. We consider a cost proportional to (the absolute value of) a household's expected utility, $(\chi-1)\left|q u\left(c_{1}\right)+(1-q) u\left(c_{2}\right)\right|$, where $\chi \geq 1 .^{5}$ Such a cost could represent a household's effort or resource spent on enhancing its investing ability, in general, and on learning to distinguish an asset from a fake, in particular. The size of $\chi$ could be affected by the development of financial markets, or the extent to

\footnotetext{
${ }^{4}$ There is no premature liquidation of this technology possible at $t=1$. This implies, in particular, that self-fulfilling bank runs do not occur.

${ }^{5}$ Assuming a proportional cost helps obtain analytical results. The analysis in the case of a proportional resource cost or a fixed utility cost yields similar insights. These robustness checks are available from the authors.
} 
which financial instruments are standardized, among other things. We consider $\chi$ as exogenously determined.

\subsection{Banks}

Households can also deposit their endowment in a bank. There is a large number of banks competing for households' deposits. Banks invest the deposits they have received in storage or in the productive technology. They can also trade in the secondary financial market at date 1. Banks can distinguish real from fake assets costlessly. Thus, banks obtain a return of $R$ for the claims they hold. ${ }^{6}$

As in Diamond and Rajan (2001), banks can credibly commit to pay this return to a third party by setting up a deposit contract. Such a contract exposes banks to runs if they attempt to renegotiate the repayments they have promised depositors. ${ }^{7}$ Thus, one role of banks in this environment is to intermediate investment for unsophisticated households and thus allow them to indirectly invest in the productive technology, as in Diamond and Rajan (2000, 2001). Additionally, in this setup banks can provide liquidity insurance to depositors who do not know whether they will be patient or impatient, as in Diamond and Dybvig (1983). ${ }^{8}$

\footnotetext{
${ }^{6}$ It is possible to endogenize the fact that banks have a smaller monitoring cost if they play the role of delegated monitors, as in Diamond (1984) or Williamson (1986). Our results do not depend on the assumption that the return banks receive from investing in the long-term technology is the same as the return sophisticated households get for such an investment. We assume these return are equal to simplify the exposition.

${ }^{7}$ Note that banks face a commitment problem similar to the one modeled in Diamond and Rajan (2001). They want to commit at date 1 to pass on the efficiency gains from costless market access to depositors. But after they have received the funds, households are locked in and banks would have an incentive to renegotiate on the repayment. However, given numerous depositors, a fixed contractual repayment, and a sequential service constraint, trying to renegotiate would always trigger a run and a disintermediation of the bank. Thus, the bank can use these financial contracts to commit to not renegotiate. See Diamond and Rajan (2000) for a more complete exposition of this argument.

${ }^{8}$ In contrast to Diamond and Dybvig, bank runs as a consequence of self-fulfilling prophecies do not occur in our model, because we do not allow for premature liquidation of capital. The effect of bank runs on growth is studied in a similar environment in Ennis and Keister (2003).
} 


\section{Equilibrium}

In this section, we study the household problem and the bank problem. Households seek to maximize their expected utility, taking as given each other's behavior and the bank deposit contract. Banks aim to maximize profits, taking as given other banks' deposit contracts and household behavior. We consider Nash equilibria.

\subsection{The price of financial assets at date 1}

The price of claims on the productive technology in the secondary market at date 1 is determined by arbitrage.

Proposition 1 The price of claims on the productive technology in the date 1 financial market is 1 .

Proof. We show that assuming a price different than 1 must lead to a contradiction.

Suppose the price of claims is $p<1$, and compare the return to investing one unit in the storage and the productive technology. One unit invested in the storage technology at date 0 returns one unit of goods at date 1 , or it can be exchanged for $1 / p$ claims on the productive technology for a return of $R / p>R$ at date 2 . One unit invested in the productive technology at date 0 can be exchanged for $p<1$ units of goods at date 1 , or it can be held to maturity for a return of $R$. Hence, the return to investing in storage at date 0 is higher both at date 1 and at date 2 , and all agents who can trade on the financial market prefer to invest in storage. However, if there is no investment in the productive technology, $p<1$ cannot be an equilibrium price. A symmetric argument shows that $p>1$ cannot be an equilibrium price.

\subsection{The household problem}

Households decide at date 0 whether to become sophisticated and whether to invest in the productive technology or deposit in a bank. At date 1, households who have invested in the productive technology decide whether to sell their claims or hold on to them. Households who have deposited in a bank decide whether to withdraw. We solve the household problem by using backward induction. 
A bank's deposit contract promises $d_{1}$ goods to depositors who withdraw at date 1 and $d_{2}$ goods to depositors who withdraw at date 2 . We assume for now that $1 \leq d_{1} \leq d_{2} \leq R$ and we will verify below that it is indeed the case. We will also show that all households deposit in a bank at date 0 , so we only consider the problem of depositors at date 1 .

Impatient depositors withdraw at date 1 because they derive no utility from consumption later. If patient depositors withdraw, they can purchase claims on the financial market or invest in the storage technology. Since $\gamma R<1 \leq d_{1} \leq d_{2}$, unsophisticated depositors choose not to withdraw. In contrast, sophisticated depositors have an incentive to withdraw because $d_{2} \leq R d_{1}$, given that $d_{2} \leq R$ and $d_{1} \geq 1$. For simplicity, assume that these depositors withdraw even if $d_{2}=R$.

If they invest in a bank at date 0 , sophisticated households can consume $d_{1} \geq 1$ at date 1 and $d_{1} R \geq R$ at date 2 . Hence, they prefer to deposit in a bank rather than invest directly in the productive technology. Unsophisticated households choose to deposit in a bank as well, because their best alternative is the storage technology that is clearly inferior because $1 \leq d_{1} \leq d_{2}$.

To summarize, sophisticated households deposit in a bank and withdraw at date 1. Impatient sophisticated households consume $d_{1}$ at date 1 while patient sophisticated households purchase financial claims and consume $d_{1} R$ at date 2 . The expected utility of sophisticated households is given by $\chi\left[q u\left(d_{1}\right)+(1-q) u\left(d_{1} R\right)\right]$.

Unsophisticated households deposit in a bank. They withdraw and consume $d_{1}$ at date 1 if they are impatient and withdraw and consume $d_{2}$ at date 2 if they are patient. The expected utility of unsophisticated households is given by $q u\left(d_{1}\right)+(1-q) u\left(d_{2}\right)$.

\subsection{The bank problem}

Banks decide which deposit contract to offer at date 0, taking as given other banks' deposit contracts and depositors behavior. Banks offer the deposit contract at the same time as depositors decide whether to become sophisticated. ${ }^{9}$

\footnotetext{
${ }^{9}$ If banks are allowed to move first, they can offer a contract under which no household has an incentive to become sophisticated. Our results also hold in this case, as the cost of becoming sophisticated still influences the contract offered by banks, but then the secondary market is inactive.
} 
Proposition 2 Profit-maximizing competitive banks must maximize

$$
q u\left(d_{1}\right)+(1-q) u\left(d_{2}\right)
$$

Proof. That banks maximize the expected utility of unsophisticated depositors follows from two observations: First, sophisticated depositors only care about $d_{1}$ because they always withdraw at date 1 . Second, a bank that attracts only sophisticated depositors must offer $d_{1}=1$ because all its depositors withdraw at date 1 . Hence, sophisticated depositors want to deposit in banks that attract unsophisticated depositors. Banks attract unsophisticated depositors by offering a contract that maximizes their expected utility.

The deposit contract must satisfy three constraints:

$$
\begin{aligned}
{[q i+(1-i)] d_{1}+(1-q) i \frac{d_{2}}{R} } & \leq 1, \\
d_{1} & \leq d_{2}, \\
R d_{1} & \geq d_{2},
\end{aligned}
$$

where $i$ denotes the fraction of unsophisticated depositors. The feasibility constraint, given by (2), says the bank must have enough resources to pay $d_{2}$ to a fraction $1-q$ of unsophisticated depositors at date 2 and $d_{1}$ to all sophisticated depositors as well as a fraction $q$ of unsophisticated depositors at date 1. Consequently, this constraint takes into account the equilibrium behavior of the different types of households, i.e., that unsophisticated households only withdraw early if they are patient while sophisticated households always withdraw early irrespective of their preference shocks. The two incentive compatibility constraints (3) and (4) ensure that unsophisticated and sophisticated households, respectively, indeed have an incentive to behave in that way given the derived deposit contract. Constraint (3) guarantees that patient unsophisticated depositors do not withdraw at date 1 . The best patient unsophisticated depositors can do with the withdrawn fund at date 1 is to invest them in the storage technology until $t=2$. Alternatively, they could also invest the fund in assets at the equilibrium price of 1 . However, in that case they would only yield a return $\gamma R d_{1}<d_{1}$. Constraint (4) assures that patient sophisticated households are never strictly better off by keeping their deposits in the bank until date 2 . 
Any deposit contract that violates either of the constraints is not competitionproof: With a deposit contract that violates (2), banks encounter losses. If (3) does not hold and all households withdraw early, the only feasible deposit contract satisfying this would be $d_{1}=1$ and $d_{2}<\gamma R$. Thus banks, would be dominated by direct investments. A deposit contract that violates (4) provides inefficient risksharing.

Contracts that maximize (1) subject to (2) are characterized by

$$
\begin{aligned}
& d_{1}=\frac{R}{R-(R-\Theta)(1-q) i}, \\
& d_{2}=\frac{R \Theta}{R-(R-\Theta)(1-q) i},
\end{aligned}
$$

where

$$
\Theta \equiv\left[\frac{1-(1-q) i}{q i} R\right]^{\frac{1}{\alpha}} .
$$

When constraint (4) holds with equality, $\Theta=R$, and patient sophisticated depositors are indifferent between leaving their deposits in the bank and withdrawing them to invest in the secondary market. In this case, banks offer no liquidity insurance. We define

$$
\underline{i} \equiv\left[q R^{\alpha-1}+(1-q)\right]^{-1}
$$

Constraint (4) binds whenever $i \leq \underline{i}$. If this happens, the contract is given by equations (5) and (6) with $\Theta=R$.

To find the effect of a change in $i$ on $\Theta$, the amount of risk-sharing, we take the partial derivative of the latter with respect to the former.

$$
\frac{\partial \Theta}{\partial i}=-\frac{1}{\alpha} \frac{R}{q i^{2}}\left[\frac{1-(1-q) i}{q i} R\right]^{\frac{1}{\alpha}-1}<0 .
$$

Hence, an increase in the fraction of unsophisticated depositors, $i$, increases risksharing because it reduces $\Theta=d_{2} / d_{1}$.

Banks could offer better risk-sharing if they were able to prevent households from becoming sophisticated. Since in equilibrium banks sell financial assets to sophisticated depositors in the financial market, one may wonder whether banks can influence households' choice by withholding claims to the productive technology. Competition prevents this from happening. 
It cannot be an equilibrium for banks to supply fewer assets, in aggregate, than sophisticated depositors demand. If too few assets were supplied, this would put pressure on the price of assets to increase and would, in turn, give competitive banks an incentive to invest in the productive technology.

An individual bank has no incentive to hold on to financial assets it does not need to provide to its patient unsophisticated depositors. Moreover, the bank must sell these assets if it is to meet its obligation to depositors withdrawing at date 1.

\subsection{Equilibrium fraction of unsophisticated depositors}

The equilibrium value of $i$ is determined by the condition that depositors must be indifferent between becoming sophisticated or remaining unsophisticated. This condition is

$$
q u\left(d_{1}\right)+(1-q) u\left(d_{2}\right)=\chi\left[q u\left(d_{1}\right)+(1-q) u\left(d_{1} R\right)\right] .
$$

We can use equations (5) and (6) to substitute for $d_{1}$ and $d_{2}$ in that expression. Then, using the fact that $u$ is CRRA, we can write

$$
\Theta^{1-\alpha}=\chi R^{1-\alpha}+\frac{q}{1-q}(\chi-1) .
$$

Using the definition of $\Theta$, we obtain the following expression for $i$

$$
i=\left\{(1-q)+\frac{q}{R}\left[\chi\left(R^{1-\alpha}+\frac{q}{1-q}\right)-\frac{q}{1-q}\right]^{\frac{\alpha}{1-\alpha}}\right\}^{-1} .
$$

It can easily be seen that an increase in $\chi$, the cost of becoming sophisticated, will lead to an increase in $i$, the fraction of unsophisticated depositors, because

$$
\frac{\partial i}{\partial \chi}=\frac{\alpha}{\alpha-1} \frac{\frac{q}{R}\left(R^{1-\alpha}+\frac{q}{1-q}\right)\left[\chi\left(R^{1-\alpha}+\frac{q}{1-q}\right)-\frac{q}{1-q}\right]^{\frac{2 \alpha-1}{1-\alpha}}}{\left\{(1-q)+\frac{q}{R}\left[\chi\left(R^{1-\alpha}+\frac{q}{1-q}\right)-\frac{q}{1-q}\right]^{\frac{\alpha}{1-\alpha}}\right\}^{2}}>0 .
$$

As expected, $i=\underline{i}$ if there is no cost of becoming sophisticated, or $\chi=1$. We can also find the cost above which no depositor becomes sophisticated, denoted by $\bar{\chi}$, by setting $i=1$ in equation (12). We obtain

$$
\bar{\chi}=\frac{(1-q) R^{\frac{1-\alpha}{\alpha}}+q}{(1-q) R^{1-\alpha}+q}
$$


If $\chi \geq \bar{\chi}$, the cost of becoming sophisticated is so high that no depositor chooses to become sophisticated.

We can derive the amount of investment in the productive technology chosen by banks and denoted by $K$. Part of the investment, $(1-q) i\left(d_{2} / R\right)$, is needed to provide consumption for patient unsophisticated depositors who withdraw at date 2 . The rest, $(1-q)(1-i) d_{1}$, is sold to patient sophisticated depositors in the secondary market. ${ }^{10}$ The expression for $K$ is thus

$$
K(i)=1-\frac{q}{1-(1-q) i\left(1-\frac{\Theta}{R}\right)}
$$

It is decreasing in $i$ since

$$
\frac{\partial K(i)}{\partial i}=-q \frac{(1-q)\left(1-\frac{\Theta}{R}\right)-(1-q) i \frac{1}{R} \frac{\partial \Theta}{\partial i}}{\left[1-(1-q) i\left(1-\frac{\Theta}{R}\right)\right]^{2}}<0 .
$$

In particular, $K(i=\underline{i})=1-q$ and

$$
K(i=1)=1-\frac{q}{1-(1-q)\left(1-R^{\frac{1-\alpha}{\alpha}}\right)} .
$$

Note that all the initial investment in the productive technology is made by banks. In other words, only banks are active in the primary market for projects. In contrast, sophisticated investors only invest in the secondary market. Thus, the role of markets in our model and whether a financial system is bank-based or market-oriented are determined by how active sophisticated depositors are in the secondary market at date 1 .

When the cost of becoming sophisticated is high, there are few such depositors $(i$ is large) and the secondary market for financial claims is not very active. Banks are able to offer much liquidity insurance but there is relatively little investment in the productive technology. Conversely, when the cost of becoming sophisticated is low, there are many such depositors ( $i$ is small) and the secondary market is very active. Banks offer little liquidity insurance, or none at all, but there is more aggregate investment in the productive technology. Hence, when comparing two economies, $A$

\footnotetext{
${ }^{10}$ Alternatively, the level of investment in the long-term technology can be derived by considering what is not consumed at date 1 ; i.e., $K=1-q d_{1}$.
} 
and $B$, with a different fraction of sophisticated depositors, $i_{A}>i_{B}$, we say economy $A$ is more bank-oriented, or, equivalently, we say economy $B$ is more market-oriented.

The model does not provide an obvious way to compare different levels of financial development. Hence, when comparing two economies, we are implicitly assuming that the level of financial development in both economies is the same.

We can summarize the results obtained in this section in a proposition.

Proposition 3 In this economy:

1) The fraction of unsophisticated depositors increases as the cost of becoming sophisticated increases.

2) Investment in the long-term technology decreases and risk-sharing increases as the fraction of unsophisticated depositors increases.

Allen and Gale (1997) study an environment in which the market constrains how much risk-sharing financial intermediaries can provide. In that model, they show that having intermediaries and no financial markets is preferable to having a financial market and no intermediaries. As in our static model, the intuition for their result is that more risk-sharing is provided in the former case than in the latter.

A key feature of the model in Allen and Gale (1997) is that the productive asset is in fixed supply. Hence, it is difficult to extend that environment to include growth. In contrast, it is straightforward to adapt our setup to a dynamic environment. The next section shows that there is a real trade-off between risk-sharing and growth in a dynamic environment. The result that bank-based financial systems are always better is therefore overturned in that context.

\section{An OLG environment with growth}

In this section, we embed the static model of the previous section in a two-period OLG framework along the lines of Ennis and Keister (2003). This allows us to think about how changes in the fraction of sophisticated households affect capital accumulation and growth. 


\subsection{The OLG model}

Households' preferences are the same as in the static model but endowments and technologies differ. Young households are endowed with one unit of labor that is supplied inelastically. Old households receive no endowment. There are two goods in the OLG economy: A consumption good and capital. Capital cannot be consumed. Capital and labor can be combined to produce the consumption good according to an endogenous-growth production function:

$$
Y_{t}=\bar{K}_{t}^{1-\theta} L_{t}{ }^{1-\theta} K_{t}{ }^{\theta}
$$

where $Y_{t}$ denotes the output of the consumption good, $K_{t}$ is the capital input, $L_{t}$ is the labor input, and $\bar{K}_{t}$ denotes the capital stock of the economy at date $t$.

As in the static model, the consumption good can be stored. It can also be invested in a productive technology that transforms one unit of the consumption good into $R$ units of new capital in the next period.

We assume that a new set of banks emerges with each new generation. ${ }^{11}$ Banks operate the endogenous-growth production function and the productive technology. As in the static model, banks can costlessly distinguish real and fake assets in the financial market. Sophisticated households can also distinguish real and fake assets but unsophisticated households cannot.

The timing of events is as follows. Each period is divided into two subperiods: in the first subperiod (the beginning), production occurs according to the endogenousgrowth production function described above, factors get paid, and young households can deposit their wage income in one of a large number of perfectly competitive banks. Banks can use deposits to purchase existing capital from old households, to invest in new capital, or to invest in storage. In the second subperiod (the end), depositors observe whether they are patient or impatient and they can withdraw their deposits from the bank. We now describe some details.

The beginning of period $t$ : At the beginning of period $t$, the capital stock is in the hands of the old, patient sophisticated households and the banks. Patient

\footnotetext{
${ }^{11}$ Note that as in Ennis and Keister (2003), but in contrast to Allen and Gale (1997) or Bhattacharya and Padilla (1996), there is no intergenerational risk-sharing in this model.
} 
sophisticated households own claims that they have purchased in the financial market in period $t-1$. Banks hold capital on behalf of patient unsophisticated depositors. Young households are endowed with $L_{t}=1$ units of time.

Banks use the capital they hold and rent capital from sophisticated households to combine it with labor to produce the consumption good. After production takes place, patient sophisticated households can obtain consumption goods equal to the earnings from renting their capital and selling the net-of-depreciation value of that capital. Hence, a patient sophisticated household starting period $t$ with $K_{t}$ units of capital receives $\left[r_{t}+(1-\delta) p_{t}^{-}\right] K_{t}$ units of the consumption good, where $p_{t}^{-}$denotes the price of capital in units of the consumption good in the beginning-of-period capital market. The amount of the consumption good received by patient unsophisticated households is determined by the deposit contract.

Each young household receives $w_{t}$ units of the consumption good as its wage. Young households deposit their wage income in a perfectly competitive bank and enter a deposit contract $\left(d_{1 t}, d_{2 t}\right)$ before they find out whether they are patient or impatient. It is optimal for households to deposit all their income in banks. The bank uses a portion of the deposits to purchase existing capital at the price $p_{t}^{-}$from old sophisticated households, and divides the rest of the deposits between storage and investment in new capital via the productive technology. One unit of the consumption good placed in storage at the beginning of period $t$ yields one unit of the consumption good at the end of the same period, while one unit of the consumption good invested in the productive technology at the beginning of period $t$ yields $R>1$ units of capital at the beginning of period $t+1$. Note that investment in the productive technology is the only way to produce new capital. The assumption that only banks engage in purchasing existing capital, investing in the productive technology, and putting goods in storage at the beginning of the period is innocuous.

As in the static model, young households decide whether or not to become sophisticated at the same time banks offer the deposit contract $\left(d_{1 t}, d_{2 t}\right)$, and there is a proportional utility cost of becoming sophisticated. ${ }^{12}$

\footnotetext{
${ }^{12}$ Results in the case of a proportional resource cost or a fixed utility cost are similar, and are available from the authors.
} 
The end of period $t$ : Young depositors realize whether they are patient or impatient. Impatient depositors only value consumption in this subperiod, while patient depositors only value consumption in the first subperiod of $t+1$. As in the static model, patient sophisticated depositors claim to be impatient and banks are unable to prevent them from withdrawing. Sophisticated depositors who withdraw at date $t$ can purchase capital from banks at a price $p_{t}^{+}$.

Let $X_{t}$ denote the one-period return to investing in a real asset on the secondary market at date $t$. We show below that $X_{t}$ is constant, so we can drop the time subscript. The optimal contract offered by banks is essentially the same as in the previous section with $X$ replacing $R$ in the expressions below. Taking $i_{t}$ as given, the problem for a profit-maximizing competitive bank is

$$
\begin{array}{rlr}
\max _{d_{1 t}, d_{2 t}} & q u\left(d_{1 t}\right)+(1-q) u\left(d_{2 t}\right) \\
\text { s.t. } & {\left[q i_{t}+\left(1-i_{t}\right)\right] d_{1 t}+(1-q) i_{t} \frac{d_{2 t}}{X} \leq w_{t}, \quad(B C)} \\
& \max \{1, X\} d_{1 t} \geq d_{2 t}, \quad\left(I C_{S}\right) \\
& \max \{1, \gamma X\} d_{1 t} \leq d_{2 t} .
\end{array}
$$

\subsection{Equilibrium}

We turn now to the characterization of an equilibrium. The assumption of perfect competition in the factor markets, and the fact that labor is supplied inelastically, implies that the equilibrium real wage is given by $w_{t}=(1-\theta) K_{t}$ and the real rental rate on capital in units of the consumption good is $r_{t}=\theta$.

An arbitrage argument similar to the one in proposition 1 shows that the price of existing capital in the primary and the secondary markets must be such that

$$
p_{t}^{-}=p_{t}^{+}=\frac{1}{R}, \quad \forall t .^{13}
$$

The expression for $X$, the one-period return to investing in a real asset on the

\footnotetext{
${ }^{13}$ Note that an equilibrium could exist in which there is no investment in new capital and the price of capital in the secondary market is less than $1 / R$. In this paper, we focus on equilibria with investment in new capital because this is a necessary condition for the economy to grow.
} 
secondary market, is given by

$$
X \equiv R\left[r_{t}+(1-\delta) p_{t}^{-}\right]=R\left[\theta+(1-\delta) R^{-1}\right]=R \theta+1-\delta
$$

One unit of capital at the beginning of period $t$ can be rented to earn $r_{t}$ and the undepreciated capital can then be sold to banks at the price $p_{t}^{-}$. This yields an amount $r_{t}+(1-\delta) p_{t}^{-}$of the consumption good at the end of the first subperiod in $t$. The consumption good can then be invested in the long-term technology to produce new capital at the beginning of period $t+1$. We choose our parameters such that $X>1$ and $\gamma X<1$. Note, $X>1$ implies $r_{t} \geq \delta p_{t}^{-}$, the condition for old households to strictly prefer renting their capital before selling it to banks.

Next, we characterize the deposit contract. Maximizing a bank's objective function subject to constraint $(\mathrm{BC})$ yields:

$$
\begin{aligned}
d_{1 t} & =\frac{X(1-\theta) K_{t}}{X-\left(X-\Theta_{t}\right)(1-q) i_{t}}, \\
d_{2 t} & =\frac{X \Theta_{t}(1-\theta) K_{t}}{X-\left(X-\Theta_{t}\right)(1-q) i_{t}} .
\end{aligned}
$$

The definitions of $\Theta_{t}$ and $\underline{i}$ are similar to those in the static model.

$$
\begin{aligned}
\Theta_{t} & \equiv\left[\frac{1-(1-q) i_{t}}{q i_{t}} X\right]^{\frac{1}{\alpha}} \\
\underline{i} & \equiv\left[q X^{\alpha-1}+(1-q)\right]^{-1} .
\end{aligned}
$$

Taking the deposit contract as given, $i_{t}$ is determined by

$$
q u\left(d_{1 t}\right)+(1-q) u\left(d_{2 t}\right)=\chi\left[q u\left(d_{1 t}\right)+(1-q) u\left(d_{1 t} X\right)\right] .
$$

The expression for $\bar{\chi}$ is now

$$
\bar{\chi}=\frac{(1-q) X^{\frac{1-\alpha}{\alpha}}+q}{(1-q) X^{1-\alpha}+q} .
$$

We consider $\chi \in[1, \bar{\chi}]$, which guarantees that the endogenously determined $i_{t}$ lies in the interval $[\underline{i}, 1]$. To see this, substitute (21) and (22) into (25) to obtain

$$
i_{t}=\frac{X}{(1-q) X+q A},
$$


where $A$ is given by

$$
A \equiv\left[\frac{q(\chi-1)+\chi(1-q) X^{1-\alpha}}{1-q}\right]^{\frac{\alpha}{1-\alpha}} .
$$

For the remainder of the paper, we drop the indexes for $i_{t}$ and $\Theta_{t}$ since they are time-invariant.

We focus on a symmetric equilibrium in which each bank holds the same portfolio. The law of motion for capital is given by

$$
\begin{aligned}
K_{t+1} & =(1-q)(1-i) \frac{d_{1 t}}{p_{t}^{+}}+(1-q) i \frac{d_{2 t}}{X} R \\
& =\frac{X-(X-\Theta) i}{X-(X-\Theta)(1-q) i} R(1-q)(1-\theta) K_{t} \\
& =\frac{\Theta-q X+q A}{(1-q) \Theta+q A} R(1-q)(1-\theta) K_{t} \equiv \rho K_{t} .
\end{aligned}
$$

Proposition 4 The growth rate of the economy decreases with the cost to become sophisticated, that is,

$$
\frac{\partial \rho}{\partial \chi}<0
$$

The proof is provided in the appendix. This proposition indicates that economies with a smaller fraction of unsophisticated depositors grow faster than economies with a larger fraction. Intuitively, a larger cost of becoming sophisticated results in less sophisticated households participating in the capital market. There is less investment in the productive technology and thus a smaller growth rate. ${ }^{14}$

\subsection{Welfare}

While we have established that a market-oriented financial system promotes growth in our model economy, there is no guarantee that such a system also improves welfare. Indeed, the increase in growth comes at a cost of reduced risk-sharing. In this section, we consider the mix of banks and markets that provides the highest welfare.

The welfare criterion we consider is the discounted sum of the expected utility of all generations, where the expected utility of future generations is discounted by

\footnotetext{
${ }^{14}$ We can impose restrictions on the parameters such that the growth rate is greater than or equal to $1-\delta$ for all $\chi \in[1, \bar{\chi}]$. This implies that the market clears.
} 
a social discount factor $\beta \in(0,1) .{ }^{15}$ Since the indifference condition (25) implies that, in equilibrium, the expected utility of sophisticated depositors is equal to the expected utility of unsophisticated depositors, social welfare is equal to

$$
W=u\left(\left[\theta+R^{-1}(1-\delta)\right] K_{1}\right)+\sum_{t=1}^{\infty} \beta^{t}\left[q u\left(d_{1 t}\right)+(1-q) u\left(d_{2 t}\right)\right] .
$$

The first term represents the utility of the initial old households and $K_{1}$ denotes the initial stock of capital. As this term does not affect the subsequent analysis, it is omitted hereafter. Note,

$$
\left(d_{1 t}, d_{2 t}\right)=\left(G \rho^{t-1}, \Theta G \rho^{t-1}\right), \quad \text { where } \quad G \equiv \frac{X(1-\theta) K_{1}}{X-(X-\Theta)(1-q) i}
$$

and

$$
\frac{\partial G}{\partial \chi}=\frac{X(1-\theta) K_{1}}{[X-(X-\Theta)(1-q) i]^{2}}\left[(X-\Theta)(1-q)-(1-q) i \frac{\partial \Theta}{\partial \chi} \frac{\partial i}{\partial \chi}\right]>0 .
$$

Hence, we have the following relationships:

$$
\frac{\partial \rho}{\partial \chi}<0, \quad \frac{\partial \Theta}{\partial \chi}<0, \quad \frac{\partial G}{\partial \chi}>0, \quad \frac{\partial i}{\partial \chi}>0
$$

Increasing the cost of becoming sophisticated (i.e., increasing $\chi$ ) has an ambiguous effect on $d_{1 t}$ and $d_{2 t}$ as it simultaneously increases $G$ and decreases $\rho$. At $t=1$, only the effect on $G$ is present and thus a larger cost of becoming sophisticated increases the expected utility of this generation, as in the static model. If $\rho>1$, an increase in $\chi$ decreases $d_{1 t}$ and $d_{2 t}$ for sufficiently large $t$.

An increase in $\chi$ also decreases $\Theta$, which corresponds to more risk-sharing, as in the static model. It follows that an increase in the cost of becoming sophisticated simultaneously increases risk-sharing and decreases growth, leading to a trade-off between the two effects.

We are interested in the effect on welfare of a change in the cost $\chi$. A given value for $\chi$ results in a particular mix of markets and banks, and we are interested in

\footnotetext{
${ }^{15}$ There are several possible choices of a welfare function in an overlapping-generations model. The approach we choose is quite common and has the advantage of being simple and tractable. Contrary to some other criteria, our criterion takes into account all types and all generations of agents, including the initial old generation.
} 
knowing which $\chi$ corresponds to an optimal structure in the sense that the resulting balance between growth and risk-sharing maximizes the social welfare.

Assuming $\beta<\rho^{\alpha-1}$, we can solve for the social welfare as

$$
W=\frac{\beta}{1-\alpha} \frac{G^{1-\alpha}\left[q+(1-q) \Theta^{1-\alpha}\right]}{\rho^{\alpha-1}-\beta} .
$$

There exists a value of $\chi$ that maximizes $W$ since $W$ is a continuous function on the compact domain of the cost. It is also clear that such an "optimal" cost is a function of $q, X, \theta, \delta, \alpha$, and $\beta$, but is independent of the initial capital $K_{1}$. Given the complexity of equation (34) and the dependence of $\mathrm{G}, \rho, \Theta$, and $i$ on $\chi$, we are unable to obtain analytical results for the value of $\chi$ that maximizes the social welfare. Instead, we rely on numerical examples to get an idea about the trade-off between risk-sharing and growth in enhancing welfare. We assume that a period in the model corresponds to 30 years. Parameters for the production function are standard in the macro literature: we choose $\theta=0.33$ and $\delta=0.96$. The latter corresponds to a 10 percent annual capital depreciation rate over 30 years. Recall that in equilibrium $r=\theta$. We also choose $R=10$, corresponding to a value of $X=3.34$. This yields an annualized rate of return on capital of about 4 percent. Note that the inequality $r R>\delta$ is satisfied. Our baseline values for preference parameters are $\alpha=3, q=0.2$, and $\beta=0.55$. We conduct extensive sensitivity checks over the parameter space, and find that our main results are robust.

We find that social welfare associated with different values of $\chi$ is not monotone. For our baseline parameterization, welfare decreases at first with an increase in $\chi$, then increases and reaches a maximum at a value of $\chi$ that implies 88 percent of agents choose to stay unsophisticated, and then decreases again as $\chi$ increases further.

We vary the value of $\alpha$ to see how it affects the maximizing value of $\chi$. When risk aversion is low, $\alpha=2$, welfare is maximized at a lower value of $\chi$ that implies only 61 percent of agents choose to stay unsophisticated and banks offer no risk-sharing. In contrast, if risk aversion is high, $\alpha=5, \chi$ should be high enough so that no household chooses to become sophisticated. In this case, banks are not constrained in the amount of risk-sharing they can provide but growth is slow.

In another exercise, we vary $q$, the fraction of impatient households, while keeping 
all other parameters at their baseline values. If $q$ is small enough, $q=0.1$, welfare is maximized when no households become sophisticated and banks are unconstrained. If $q$ is high enough, $q=0.3$, then welfare is maximized if banks provide no risk-sharing and growth is high. This result could arise from the fact that banks provide little risk-sharing when $q$ is small, so that growth is fast even when no households become sophisticated. In that case, constraining banks provides little additional benefit. When $q$ is larger, the benefit from constraining banks increases.

We perform the same set of experiments in a model where households must pay a proportional resource cost to become sophisticated. Our results are similar. With a proportional resource cost, our numerical results suggest that welfare is a convex function of $\chi$. For our baseline parameterization, welfare is almost the same with no risk-sharing or with unconstrained risk-sharing by banks, suggesting that either extreme case is better than intermediate cases.

To summarize, we find that welfare may not be monotone in the cost of becoming sophisticated because of the trade-off between risk-sharing and growth. As a consequence, different types of financial structures can be optimal in our model, depending on parameter values.

\section{Summary and conclusion}

This paper contributes to the literature comparing the relative performance of financial intermediaries and markets by studying an environment in which a trade-off between risk-sharing and growth arises endogenously. Our model is consistent with recent evidence suggesting that market-oriented financial systems promote growth compared with more bank-oriented systems in countries with "flexible" legal systems (see Ergungor forthcoming).

If a benevolent government can influence the cost of having access to markets, then the policy implication of our model is clear. The government should influence the financial structure in order to have an optimal level of bank dominance. The government could affect the financial system by modifying the costs of investing directly in the financial market. For example, the cost of investing in the market could 
be lowered by introducing more transparent accounting standards or implementing corporate governance codes that provide better investor protection. In this way, the government would reduce the effort required from investors to efficiently select and monitor their investments. Similarly, the costs of access to markets could be increased by imposing restrictions on who is allowed to buy and trade financial claims. How bank-oriented a particular financial system should be depends on the economy's deep parameters. 


\section{Appendix A}

\subsection{Proof of proposition 4}

We want to show that $\partial \rho / \partial \chi<0$. Note that

$$
\begin{aligned}
\frac{\partial \rho}{\partial \chi} & =\frac{\left[\frac{\partial \Theta}{\partial i} \frac{\partial i}{\partial \chi}+q \frac{\partial A}{\partial \chi}\right][(1-q) \Theta+q A]-\left[(1-q) \frac{\partial \Theta}{\partial i} \frac{\partial i}{\partial \chi}+q \frac{\partial A}{\partial \chi}\right][\Theta-q X+q A]}{[(1-q) \Theta+q A]^{2}} \\
& =\frac{\frac{\partial \Theta}{\partial i} \frac{\partial i}{\partial \chi} q[q A+(1-q) X]+\frac{\partial A}{\partial \chi} q^{2}[X-\Theta]}{[(1-q) \Theta+q A]^{2}} .
\end{aligned}
$$

We already know that $\partial \Theta / \partial i<0$. Thus, the above expression is negative if $\partial i / \partial \chi>0$ and $\partial A / \partial \chi<0$. We have

$$
\frac{\partial A}{\partial \chi}=\frac{\alpha}{1-\alpha} \frac{1}{1-q}\left[q+(1-q) X^{1-\alpha}\right]\left[\frac{q(\chi-1)+\chi(1-q) X^{1-\alpha}}{1-q}\right]^{\frac{\alpha}{1-\alpha}-1}<0
$$

since $\alpha>1$. Also,

$$
\frac{\partial i}{\partial \chi}=-\frac{X}{[(1-q) X+q A]^{2}} q \frac{\partial A}{\partial \chi}>0
$$

\section{Appendix B}

\subsection{The resource-cost case}

\subsubsection{The static model}

In this setup, a young household that decides to become sophisticated at the beginning of period $t$ will incur a $(1-C)$ percent consumption loss at the end of period $t$ or the beginning of period $t+1$, for some $C \leq 1 .{ }^{16}$ In this case, equation (10) becomes

$$
q u\left(d_{1}\right)+(1-q) u\left(d_{2}\right)=\left[q u\left(C d_{1}\right)+(1-q) u\left(C d_{1} R\right)\right] .
$$

\footnotetext{
${ }^{16}$ We assume that, at date 0 , when households decide to become sophisticated or not, they are able to commit to paying the resource cost when they receive $d_{1}$ from the bank. If the cost is paid in the endowment good at date 0 , then banks can screen households based on how much they deposit. We could assume heterogeneous endowments and costs paid at date 0 , but that would complicate the analysis without providing additional insights.
} 
We can use equations (5) and (6) to substitute for $d_{1}$ and $d_{2}$. Then, since $u$ is CRRA, we have

$$
\Theta^{1-\alpha}=C^{1-\alpha} R^{1-\alpha}+\frac{q}{1-q}\left(C^{1-\alpha}-1\right) .
$$

Using the definition of $\Theta$, we obtain the following expression for $i$

$$
i=\left\{(1-q)+\frac{q}{R}\left[C^{1-\alpha} R^{1-\alpha}+\frac{q}{1-q}\left(C^{1-\alpha}-1\right)\right]^{\frac{\alpha}{1-\alpha}}\right\}^{-1} .
$$

The remainder of the analysis is similar.

\subsubsection{The OLG environment}

All relations up to (22) are the same as in the body of the paper. Taking the deposit contract as given, the equation for determining $i_{t}$ is now given by

$$
q u\left(d_{1 t}\right)+(1-q) u\left(d_{2 t}\right)=q u\left(C d_{1 t}\right)+(1-q) u\left(C d_{1 t} R\right) .
$$

Let $\underline{C}$ denote the cost which leads to $i=1$. Then,

$$
\underline{C}=\left[\frac{(1-q) R^{-\frac{(\alpha-1)^{2}}{\alpha}}+q R^{\frac{\alpha-1}{\alpha}}}{(1-q)+q R^{\frac{\alpha-1}{\alpha}}}\right]^{\frac{1}{\alpha-1}}
$$

We consider $C \in[\underline{C}, 1]$, which guarantees that the endogenously determined $i_{t}$ lies in the interval $[\underline{i}, 1]$. To see this, substitute (21) and (22) into (38) to obtain

$$
i_{t}=\frac{R}{(1-q) R+q B}
$$

which is constant over time, where

$$
B \equiv\left[\frac{q\left(C^{1-\alpha}-1\right)+C^{1-\alpha}(1-q) R^{1-\alpha}}{1-q}\right]^{\frac{\alpha}{1-\alpha}} .
$$

It can then be verified that as $C$ varies from 1 to $\underline{C}, i_{t}$ varies from $\underline{i}$ to 1 . Note that since the corresponding $\Theta_{t}>1$ and $\gamma R<1$, the solution in (21) and (22) satisfies $\left(I C_{U}\right)$. The solution also satisfies $\left(I C_{S}\right)$ since $R \geq \Theta_{t}$. Note also that since $i_{t} \leq 1$, we have $\Theta_{t} \geq R^{1 / \alpha}$. We again drop the indexes for $i_{t}$ and $\Theta_{t}$ since they are time independent. 
Since $B$ is increasing in $C, i$ is decreasing in the cost to become sophisticated. In words, the smaller $C$ is, the larger is the fraction of households who choose to become sophisticated.

The analysis so far is homomorphic to the case with a utility cost, with the underlying linkage $C^{1-\alpha}=\chi$. The implication for capital accumulation is, however, somewhat different with a resource cost. We shall again focus on a symmetric equilibrium in which each bank holds identical portfolio. The law of motion for capital is now given by

$$
\begin{aligned}
K_{t+1} & =(1-q)(1-i) C \frac{d_{1 t}}{p_{t}^{+}}+(1-q) i \frac{d_{2 t}}{R} X \\
& =\frac{C R-(C R-\Theta) i}{R-(R-\Theta)(1-q) i} X(1-q)(1-\theta) K_{t} \\
& =\frac{\Theta-q C R+q C B}{(1-q) \Theta+q B} X(1-q)(1-\theta) K_{t} \equiv \rho K_{t} .
\end{aligned}
$$

Unlike in the case with a utility cost there are here two opposite effects of a resource cost on the growth rate, $\rho$. With a smaller cost to become sophisticated, more households want to become sophisticated. This tends to help investment and growth. On the other hand, as more households become sophisticated, they use resources to pay the cost. It can be shown that the positive effect always dominates the negative effect. Hence, the growth rate is strictly increasing in $C$.

The expression for welfare in this case is similar to the utility-cost case. The following relations can be derived,

$$
\rho^{\prime}(C)>0, \quad \Theta^{\prime}(C)>0, \quad G^{\prime}(C)<0, \quad i^{\prime}(C)<0 .
$$

We run a similar set of numerical experiments for this resource-cost case as we do for the utility-cost case, using the same set of baseline parameter values, and obtain similar results.

\subsection{The fixed-cost case}

\subsubsection{The static model}

We consider the case with a fixed resource cost, as basic conclusions for the case with a fixed utility cost are similar. In this setup, a young household that decides to 
become sophisticated at the beginning of period 0 will incur $c$ units of consumption loss at the end of period 0 or the beginning of period 1 , for some $c \leq d_{1} \cdot{ }^{17}$ In this case, equation (10) becomes

$$
q u\left(d_{1}\right)+(1-q) u\left(d_{2}\right)=q u\left(d_{1}-c\right)+(1-q) u\left(R\left(d_{1}-c\right)\right) .
$$

Rearranging, we get

$$
d_{1}=\Gamma\left(d_{1}-c\right)
$$

where

$$
\Gamma=\left[\frac{q+(1-q) R^{1-\alpha}}{q+(1-q) \Theta^{1-\alpha}}\right]^{\frac{1}{1-\alpha}} \geq 1 .
$$

We can isolate $c$ on the LHS:

$$
c=d_{1} \frac{\Gamma-1}{\Gamma} .
$$

The RHS is a function of $i$ so we can differentiate the LHS with respect to $c$ and the RHS with respect to $i$ to obtain the partial derivative $\partial i / \partial c$.

Note that

$$
\begin{aligned}
\frac{\partial \Gamma}{\partial i} & =-\left[q+(1-q) R^{1-\alpha}\right]^{\frac{1}{1-\alpha}}\left[q+(1-q) \Theta^{1-\alpha}\right]^{\frac{1}{1-\alpha}-1}(1-q) \Theta^{-\alpha} \frac{\partial \Theta}{\partial i}>0, \\
\frac{\partial d_{1}}{\partial i} & =-R[R-(R-\Theta)(1-q) i]^{-2}\left[\frac{\partial \Theta}{\partial i}(1-q) i-(R-\Theta)(1-q)\right]>0,
\end{aligned}
$$

since we know that $\partial \Theta / \partial i<0$.

Now we have

$$
d c=\frac{\Gamma-1}{\Gamma} \frac{\partial d_{1}}{\partial i} d i+d_{1} \frac{\frac{\partial \Gamma}{\partial i} \Gamma-(\Gamma-1) \frac{\partial \Gamma}{\partial i}}{\Gamma^{2}} d i=\left[\frac{\Gamma-1}{\Gamma} \frac{\partial d_{1}}{\partial i}+d_{1} \frac{\frac{\partial \Gamma}{\partial i}}{\Gamma^{2}}\right] d i .
$$

The term in brackets is positive so $\partial i / \partial c \geq 0$. The remainder of the analysis is similar.

\subsubsection{The OLG environment}

We consider the case with a fixed utility cost, as basic conclusions for the case with a fixed resource cost are similar. In this setup, a young agent who decides to become

\footnotetext{
${ }^{17}$ In a Nash equilibrium agents observe the terms of the contract, and if $c$ is greater than $d_{1}$, then no agent will choose to become sophisticated. We consider only the interesting case with $c \leq d_{1}$.
} 
sophisticated at the beginning of period $t$ will incur $(1-q) U /(a-1)$ units of utility cost at the end of period $t$ or the beginning of period $t+1$. In this case, all relations up to (22) are the same as in the text of the paper, and the condition that determines the equilibrium value of $i_{t}$ is now given by

$$
q u\left(d_{1 t}\right)+(1-q) u\left(d_{2 t}\right)=q u\left(d_{1 t}\right)+(1-q) u\left(d_{1 t} X\right)-\frac{(1-q) U}{a-1} .
$$

We can manipulate equation (49) to get

$$
d_{2 t}^{1-a}=\left(d_{1 t} X\right)^{1-a}+U
$$

Substituting (21) and (22) into (50), we obtain

$$
\left[\frac{X(1-\theta) K_{t}}{1-(1-q)\left(1-F_{t}\right) i_{t}}\right]^{1-a}\left(F_{t}^{1-a}-1\right)=U
$$

where $F_{t} \equiv \Theta_{t} / X \leq 1$, where we can show that the weak inequality holds as an equality if and only if $i_{t}=\underline{i}$. Note that $F_{t}$ decreases with $i_{t}$, as $\Theta_{t}$ does.

Condition (51) prescribes $i_{t}$ as an implicit function of parameters $a, q, \theta, X$, and $U$, as well as the pre-determined variable $K_{t}$. Thus, if there is an equilibrium, then it can be solved forward sequently, starting from the beginning period, with the initial condition $K_{0}$.

It is straightforward to verify that, if $U=0$, then the only equilibrium value of $i_{t}$ is $i_{t}=\underline{i}$ (note that $F(\underline{i})=1$ ). In this case, the growth rate is a constant and equal to $R(1-q)(1-\theta)$.

Given the continuity of the right-hand side of (51) as a function of $i_{t}$, we can show that, under the same parameter restrictions alluded to in Footnote 15, and for any

$$
0 \leq U \leq\left[\frac{X(1-\theta) K_{0}}{1-(1-q)\left(1-X^{\frac{1-a}{a}}\right)}\right]^{1-a}\left[X^{\frac{(1-a)^{2}}{a}}-1\right]
$$

there is an equilibrium with growth in which $\underline{i} \leq i_{t} \leq 1$, for all $t$. For the case with $U>0$, the equilibrium value of $i_{t}$ is generally time-varying.

We now provide a local result concerning the uniqueness of equilibrium and the inverse relationship between the cost to become sophisticated and the rate of growth. 


\section{Local result}

We claim that for a small positive $U$, there exists a unique equilibrium, with the equilibrium value of $i_{t}$ satisfying (51), and the equilibrium growth rate negatively related with $U$. To prove our claim, we first obtain

$$
\frac{\partial F_{t}}{\partial i_{t}}=-\frac{\left(X F_{t}\right)^{1-a}}{a q i_{t}^{2}}
$$

which, among other things, confirms that $F_{t}$ decreases with $i_{t}$. Using this relation, we can derive the partial derivative of the left-hand side of (51) with respect to $i_{t}$ as

$$
\begin{aligned}
\frac{\partial L H S(51)}{\partial i_{t}}= & (a-1)\left[X(1-\theta) K_{t}\right]^{1-a}\left[1-(1-q)\left(1-F_{t}\right) i_{t}\right]^{a-2} \\
\times & {\left[\frac{\left(X F_{t}\right)^{1-a}}{a q \underline{i} i_{t}}-(1-q)\left(1-F_{t}\right)\left(F_{t}^{1-a}-1\right)\right] }
\end{aligned}
$$

Evaluating (54) at $U=0$, we have

$$
\left.\frac{\partial L H S(51)}{\partial i_{t}}\right|_{U=0}=\frac{(a-1)\left[X^{2}(1-\theta) K_{t}\right]^{1-a}}{a q \underline{i}^{2}}>0
$$

which suggests that, for small $U$, the left-hand side of (51) monotonically increases with $i_{t}$, and thus there is a unique value of $i_{t} \in[\underline{i}, 1]$ that satisfies (51).

Differentiating both sides of (51) with respect to $U$, and evaluating at $U=0$, we obtain

$$
\left.\frac{\partial i_{t}}{\partial U}\right|_{U=0}=\frac{a q \underline{i}^{2}}{(a-1)\left[X^{2}(1-\theta) K_{t}\right]^{1-a}}>0,
$$

which shows that, for small $U$, the fraction of unsophisticated agents, $i_{t}$, is monotonically increasing in $U$. This means that, the larger is the cost to become sophisticated, fewer agents will choose to do so. The fact that the rate of growth of the economy decreases with $i_{t}$ can be established the same way as before. Thus, a greater fraction of unsophisticated agents lead to slower growth. These together imply that, for small $U$, a larger cost to become sophisticated results in a lower growth rate.

We now provide a global result concerning the uniqueness of equilibrium and the inverse relationship between the cost to become sophisticated and the rate of growth. 


\section{Global result}

We begin by first stating the following parameter restriction:

$$
\left(1-X^{\frac{1-a}{a}}\right)\left[1-X^{-\frac{(1-a)^{2}}{a}}\right] \leq \frac{q+(1-q) X^{1-a}}{a q(1-q)}
$$

Note that many parameter specifications satisfy $(57) .{ }^{18}$

We now prove that, under (57), and for all $U$ in the range specified in (52), there exists a unique equilibrium, with the equilibrium value of $i_{t}$ satisfying (51), and the equilibrium growth rate negatively related with $U$.

We proceed by first noting that, the expression in the bracket on the right-hand side of (54) is positive if and only if

$$
\left(1-F_{t}\right)\left(1-F_{t}^{a-1}\right) i_{t}<\frac{q+(1-q) X^{1-a}}{a q(1-q)} .
$$

Using the fact that $F_{t}=\Theta_{t} / X \geq X^{1 / a} / X=X^{\frac{1-a}{a}}$ and $i_{t} \leq 1$, we have

$$
\left(1-F_{t}\right)\left(1-F_{t}^{a-1}\right) i_{t} \leq\left(1-X^{\frac{1-a}{a}}\right)\left[1-X^{-\frac{(1-a)^{2}}{a}}\right] \leq \frac{q+(1-q) X^{1-a}}{a q(1-q)}
$$

where the second inequality in (59) follows from (57). Note that the first inequality in (59) is strict except at the point where $i_{t}=1$. This means that (59) holds and, thus, the right-hand side of (54) is strictly positive for all $U$ satisfying (52) except at the upper bound. As a result, there is a unique value of $i_{t} \in[\underline{i}, 1]$ that satisfies $(51)$ for all $U$ satisfying (52).

Differentiating both sides of (51) with respect to $U$, we obtain

$$
\frac{\partial i_{t}}{\partial U}=\frac{\left[X(1-\theta) K_{t}\right]^{a-1}\left[1-(1-q)\left(1-F_{t}\right) i_{t}\right]^{2-a}}{(a-1)\left[\frac{\left(X F_{t}\right)^{1-a}}{a q \underline{i} i_{t}}-(1-q)\left(1-F_{t}\right)\left(F_{t}^{1-a}-1\right)\right]}>0 .
$$

Therefore, for all $U$ satisfying (52), the fraction of unsophisticated agents, $i_{t}$, is monotonically increasing in $U$. This means that, a larger cost to become sophisticated leads to fewer agents choosing to do so. The fact that the rate of growth of the economy decreases with $i_{t}$ can be established the same way as before. Thus, more unsophisticated agents lead to slower growth. These together imply that, for all $U$ satisfying (52), a bigger cost to become sophisticated results in slower growth.

\footnotetext{
${ }^{18}$ For instance, for $a=2$ and $X=4,(57)$ is satisfied with any $q \in[0,1]$.
} 
The remainder of the analysis is similar.

\section{Welfare analysis}

If the cost to become sophisticated is zero, then welfare evaluated at the equilibrium allocations is the same in a bank-oriented financial system and in a marketoriented financial system. It is given by

$$
\left.W\right|_{U=0}=\frac{1}{(a-1)(1-\beta)}-\frac{1}{\underline{i}(a-1)\left[X(1-\theta) K_{0}\right]^{a-1}\left\{[R(1-q)(1-\theta)]^{a-1}-\beta\right\}},
$$

for $\beta<[R(1-q)(1-\theta)]^{a-1}$, and minus infinity otherwise, where $\beta$ is the social discount factor.

If the cost to become sophisticated is positive, then welfare evaluated at the equilibrium allocations may differ in a bank-oriented financial system from that in a market-oriented financial system.

In a bank-oriented financial system, welfare is given by

$$
\left.W^{b}\right|_{U>0}=\frac{1-(1-q) U}{(a-1)(1-\beta)}-\frac{U}{i(a-1)} \sum_{t=1}^{\infty} \frac{\beta^{t-1}}{\left(F_{t}^{b}\right)^{1-a}-1} .
$$

In a market-oriented financial system, welfare is given by

$$
\left.W^{m}\right|_{U>0}=\frac{1-(1-q) U}{(a-1)(1-\beta)}-\frac{1}{\underline{i}(a-1)[X(1-\theta)]^{a-1}} \sum_{t=1}^{\infty} \frac{\beta^{t-1}}{\left(K_{t}^{m}\right)^{a-1}},
$$

where $K_{t}^{m}=[R(1-q)(1-\theta)]^{t} K_{0}$. Thus, we can rewrite $(63)$ as

$$
\left.W^{m}\right|_{U>0}=\frac{1-(1-q) U}{(a-1)(1-\beta)}-\frac{1}{\underline{i}(a-1)\left[X(1-\theta) K_{0}\right]^{a-1}\left\{[R(1-q)(1-\theta)]^{a-1}-\beta\right\}},
$$

for $\beta<[R(1-q)(1-\theta)]^{a-1}$, and minus infinity otherwise. It follows that

$W^{m}-W^{b}=\frac{1}{\underline{i}(a-1)}\left\{U \sum_{t=1}^{\infty} \frac{\beta^{t-1}}{\left(F_{t}^{b}\right)^{1-a}-1}-\frac{1}{\left[X(1-\theta) K_{0}\right]^{a-1}\left\{[R(1-q)(1-\theta)]^{a-1}-\beta\right\}}\right\}$.

As in the case with a proportional cost, a tradeoff between growth and risk-sharing arises, and an optimal financial structure may depend on the values of fundamental parameters in the model. 


\section{References}

Allen, F. and D. Gale (1995). "A welfare comparison of intermediaries and financial markets in Germany and the US." European Economic Review 39, 179 - 209.

Allen, F. and D. Gale (1997). "Financial markets, intermediaries, and intertemporal smoothing." Journal of Political Economy 105, 523 - 546.

Allen, F. and D. Gale (2000). Comparing financial systems. MIT Press.

Antinolfi, G. and E. Kawamura (2003). "Banking and markets in a monetary model." Beck, T. and R. Levine (2002). "Industry growth and capital allocation: Does having a market- or bank-based system matter?" Journal of Financial Economics 64, 147 180.

Bencivenga, V. R. and B. D. Smith (1991). "Financial intermediation and endogenous growth." Review of Economic Studies 58, 195 - 209.

Bhattacharya, S. and A. J. Padilla (1996). "Dynamic banking: A reconsideration." Review of Financial Studies 9, 1003 - 1032,

Chakraborty, S. and T. Ray (2006). "Bank-based versus market-based financial systems: A growth-theoretic analysis." Journal of Monetary Economics 53, 329 - 350.

Diamond, D. W. (1984). "Financial intermediation and delegated monitoring." $R e$ view of Economic Studies 51, 393 - 414.

Diamond, D. W. (1997). "Liquidity, banks, and markets." Journal of Political Economy 105, $928-956$.

Diamond, D. W. and P. H. Dybvig (1983). "Bank runs, deposit insurance, and liquidity," Journal of Political Economy 91, 401-419.

Diamond, D. W. and R. G. Rajan (2000). "A theory of bank capital." Journal of Finance 55, 2431 - 2465.

Diamond, D. W. and R. G. Rajan (2001). "Liquidity risk, liquidity creation, and financial fragility: A theory of banking." Journal of Political Economy 109, 287 327. 
European Central Bank (2002). Report on financial structures.

Ennis, H. M. and T. Keister (2003). "Economic growth, liquidity, and bank runs." Journal of Economic Theory 109, 220 - 245.

Ergungor, O. E. (forthcoming). "Financial system structure and economic development: Structure matters." International Review of Economics and Finance.

Fecht, F. (2004). "On the stability of different financial systems." Journal of the European Economic Association 2, 969-1014.

Freeman, S. (1985). "Transactions Costs and the Optimal Quantity of Money." Journal of Political Economy 93 146-157.

Fulghieri, P. and R. Rovelli (1998). "Capital markets, financial intermediaries, and liquidity supply." Journal of Banking and Finance 22, 1157 - 1179.

Jacklin, C. (1987). "Demand deposits, trading restrictions, and risk sharing," in: E.C. Prescott and N. Wallace, eds., Contractual arrangements for intertemporal trade, (University of Minnesota Press, Minneapolis) 26-47.

Jappelli, T. and M. Pagano (1994). "Saving, growth, and liquidity constraints." Quarterly Journal of Economics 109, 83 - 109.

Levine, R. (1991). "Stock markets, growth, and tax policy." Journal of Finance 46, $1445-1465$.

Levine, R. (1997). "Financial development and economic growth: Views and agenda." Journal of Economic Literature 35, 688 - 726.

Levine, R. (2002). "Bank-based or market-based financial systems: Which is better?" Journal of Financial Intermediation 11, 398 - 428.

Qian, Y., K. John, and T. A. John (2004). "Financial system design and liquidity provision by banks and markets in a dynamic economy." Journal of International Money and Finance 23, 385 - 403.

Williamson, S. D. (1996). "Costly monitoring, financial intermediation and equilibrium credit rationing." Journal of Monetary Economics 18, 159 - 179. 

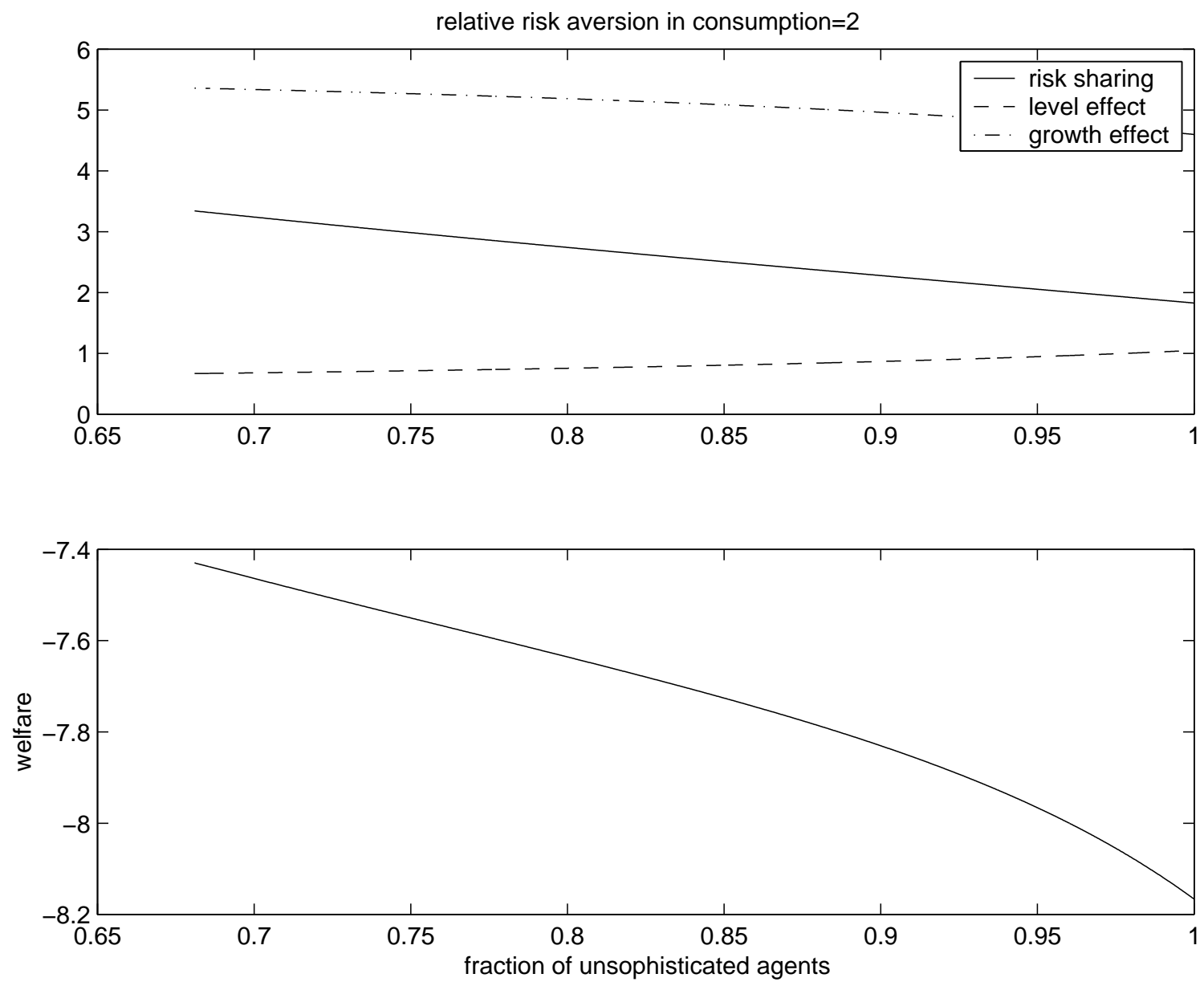

Figure 1 . The case with a utility cost 
relative risk aversion in consumption $=3$
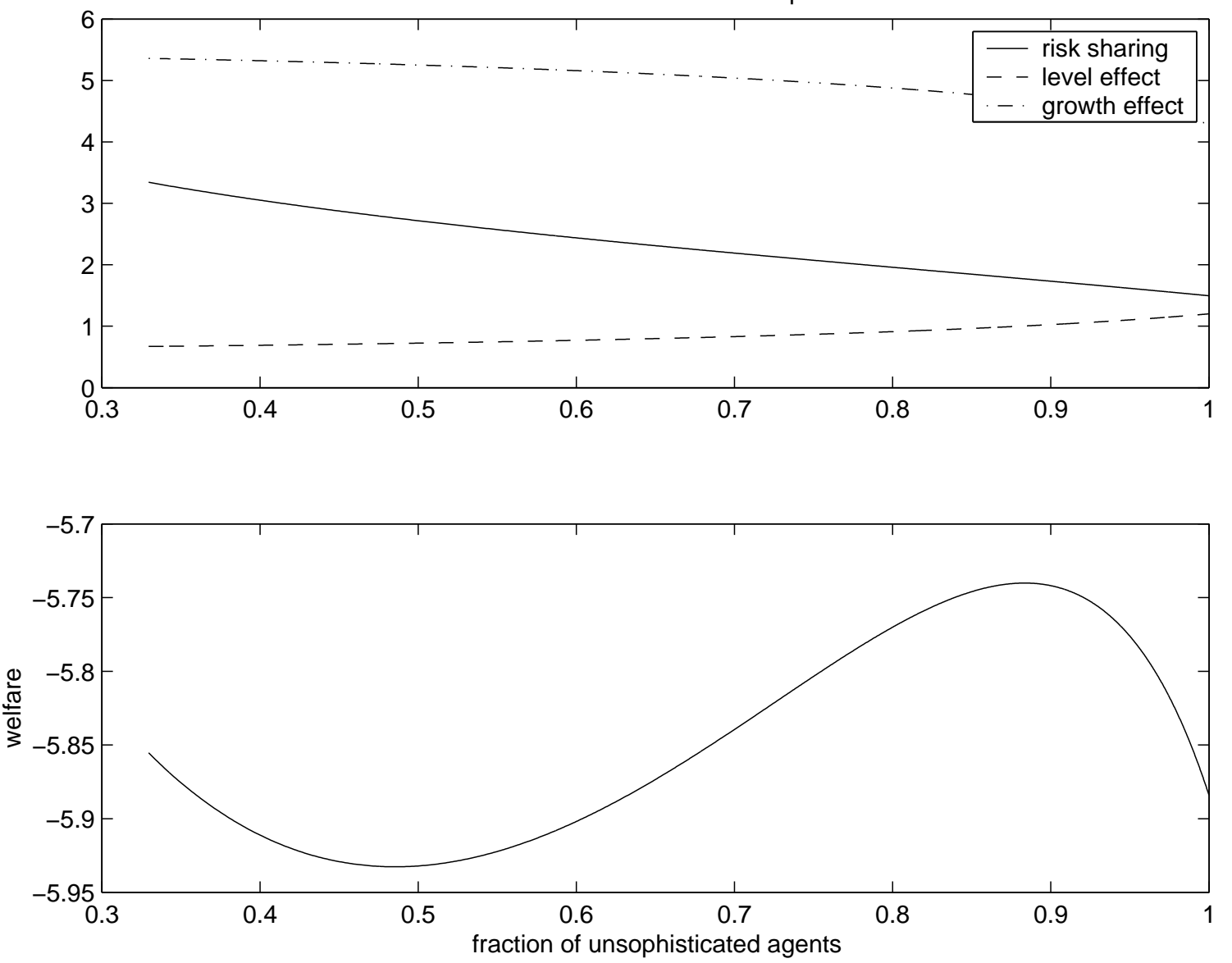

Figure 2. The case with a utility cost 

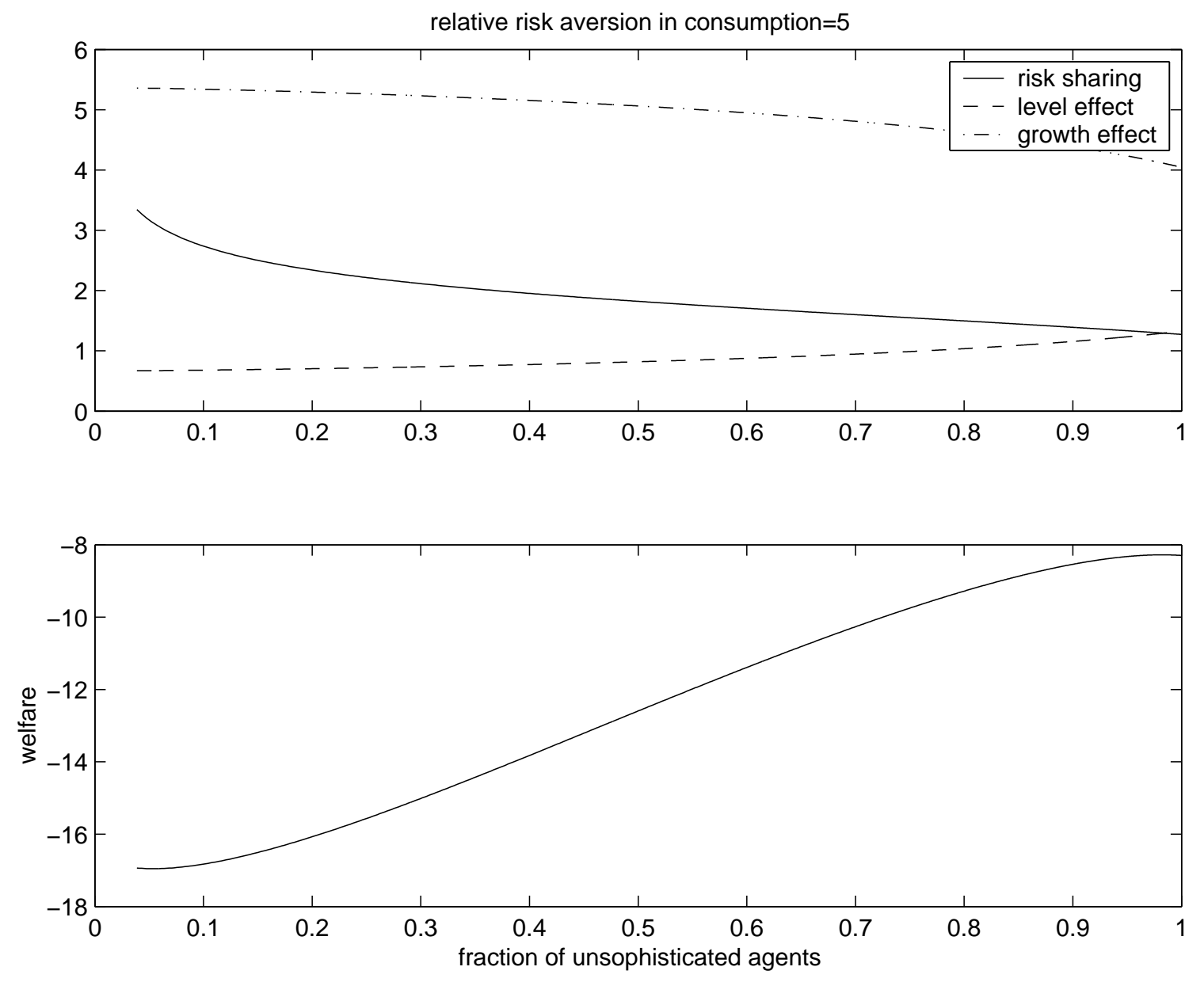

Figure 3 . The case with a utility cost 

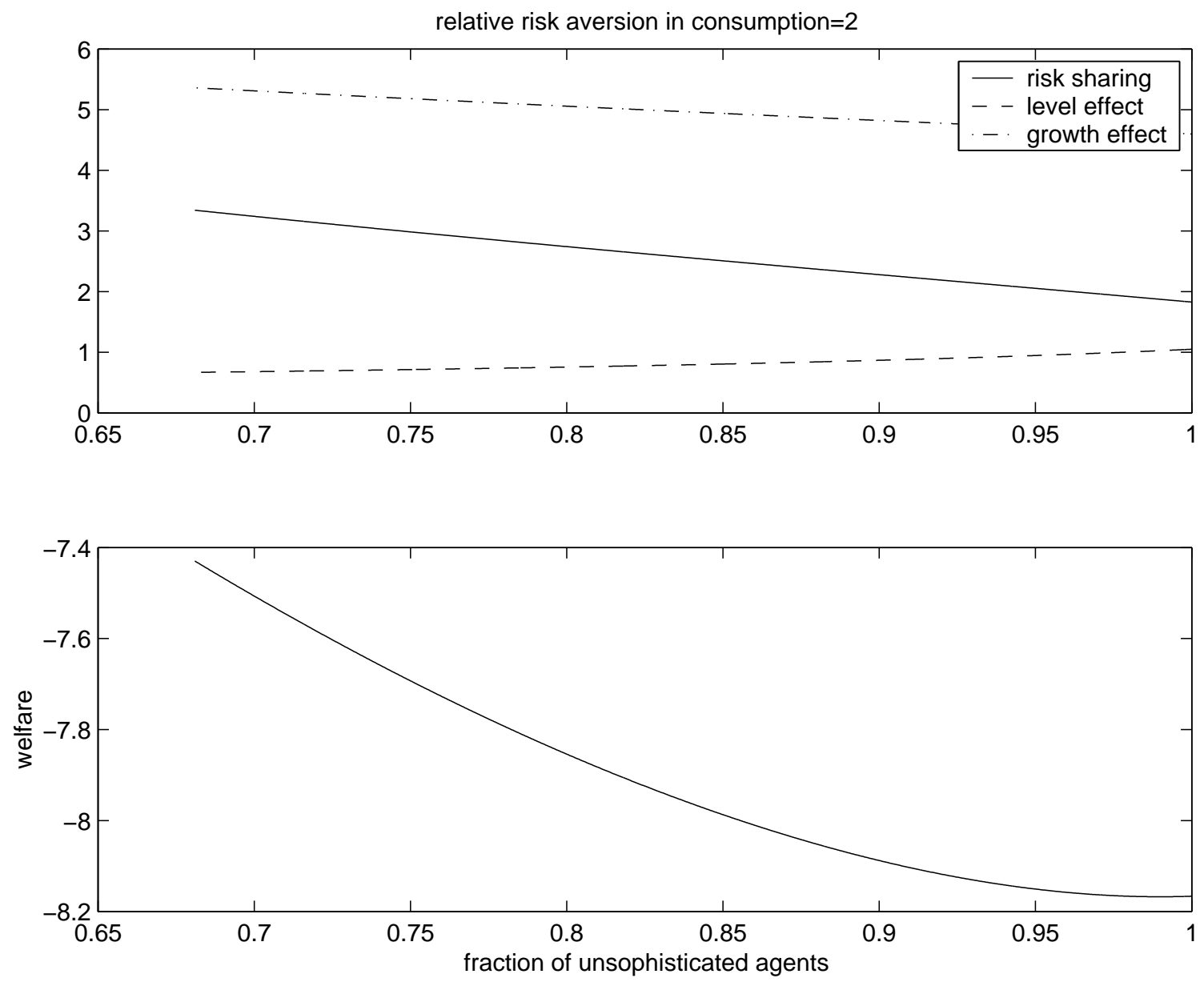

Figure 4 . The case with a resource cost 

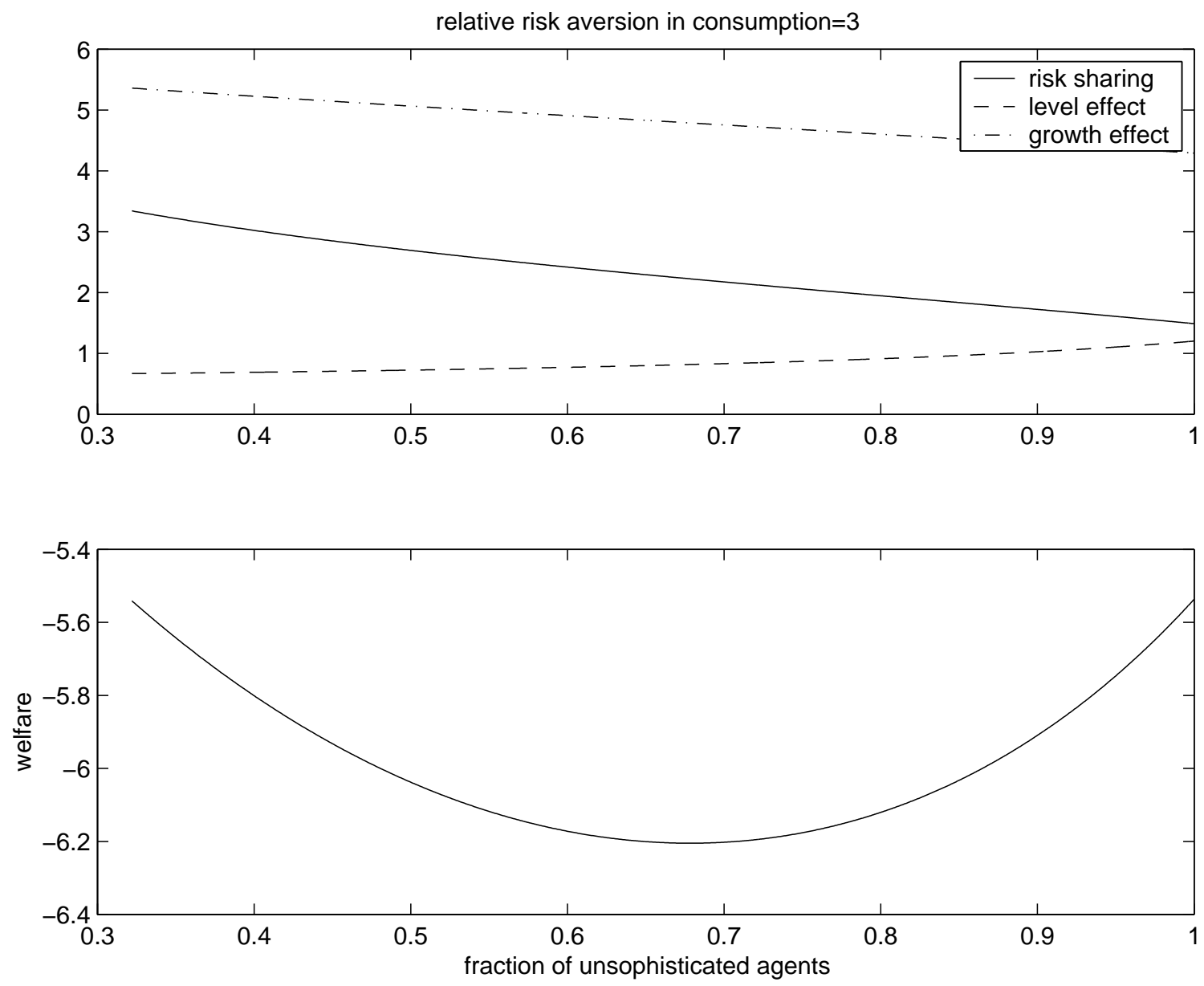

Figure 5. The case with a resource cost 

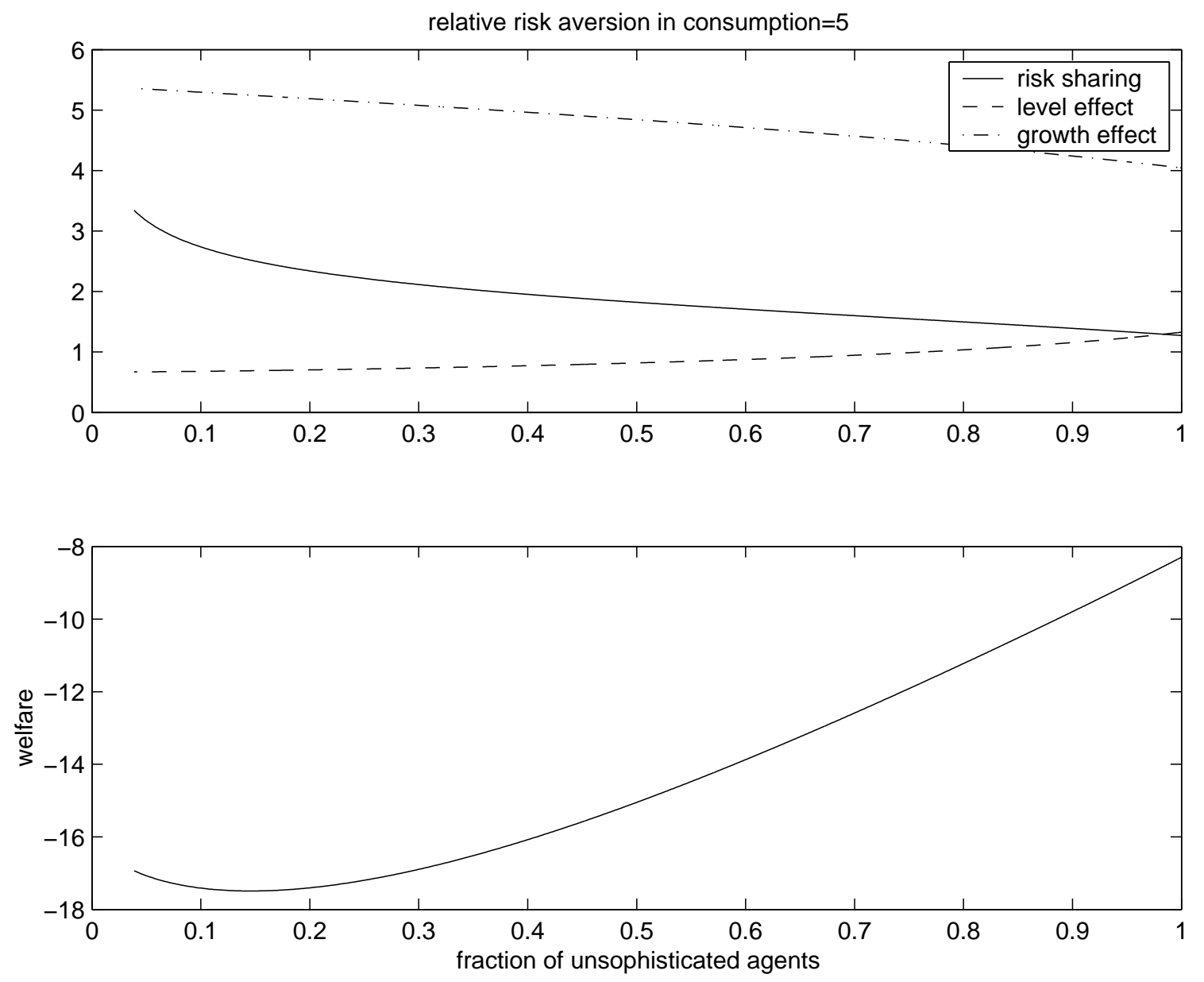

Figure 6 . The case with a resource cost 

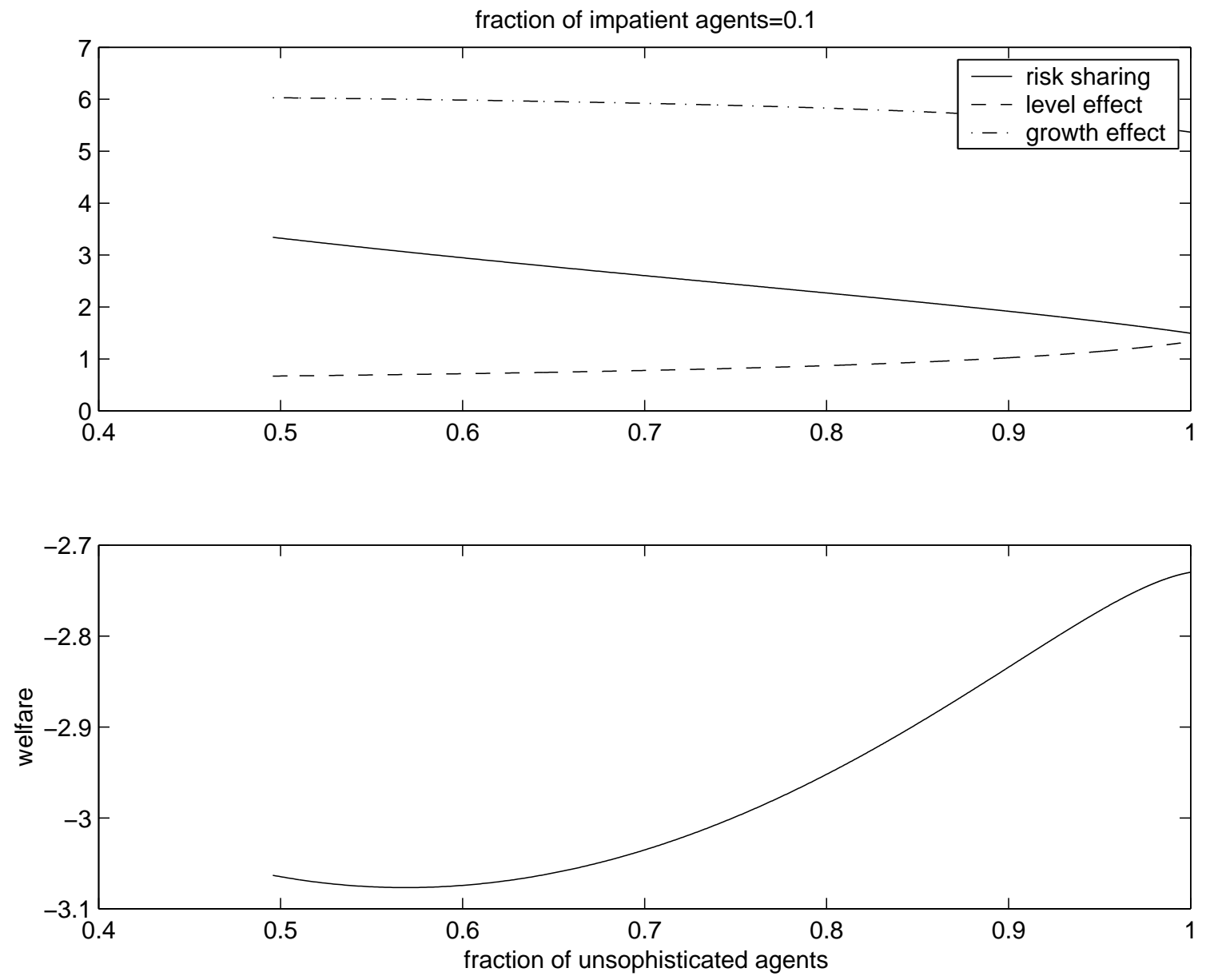

Figure 7 . The case with a utility cost 

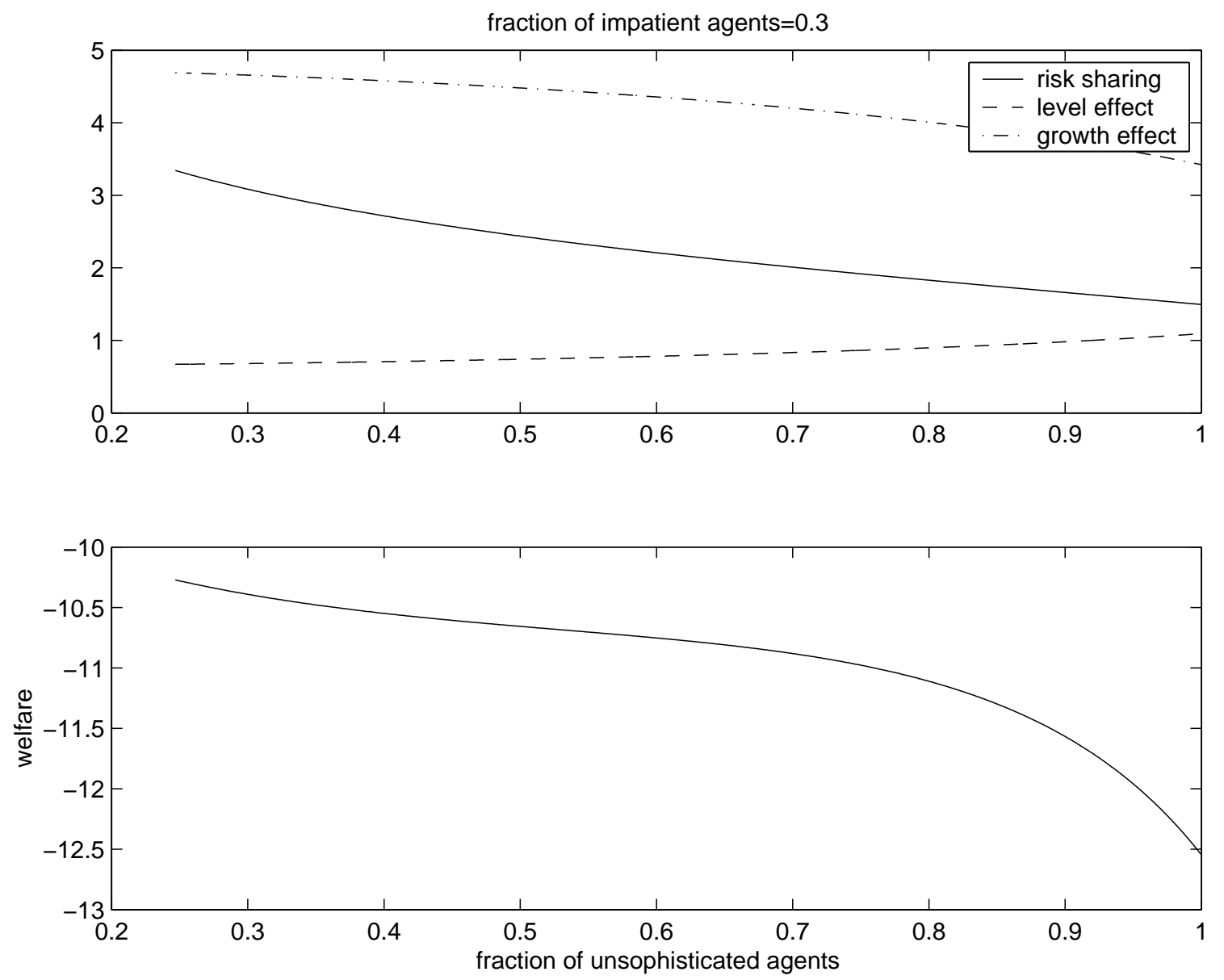

Figure 8 . The case with a utility cost 

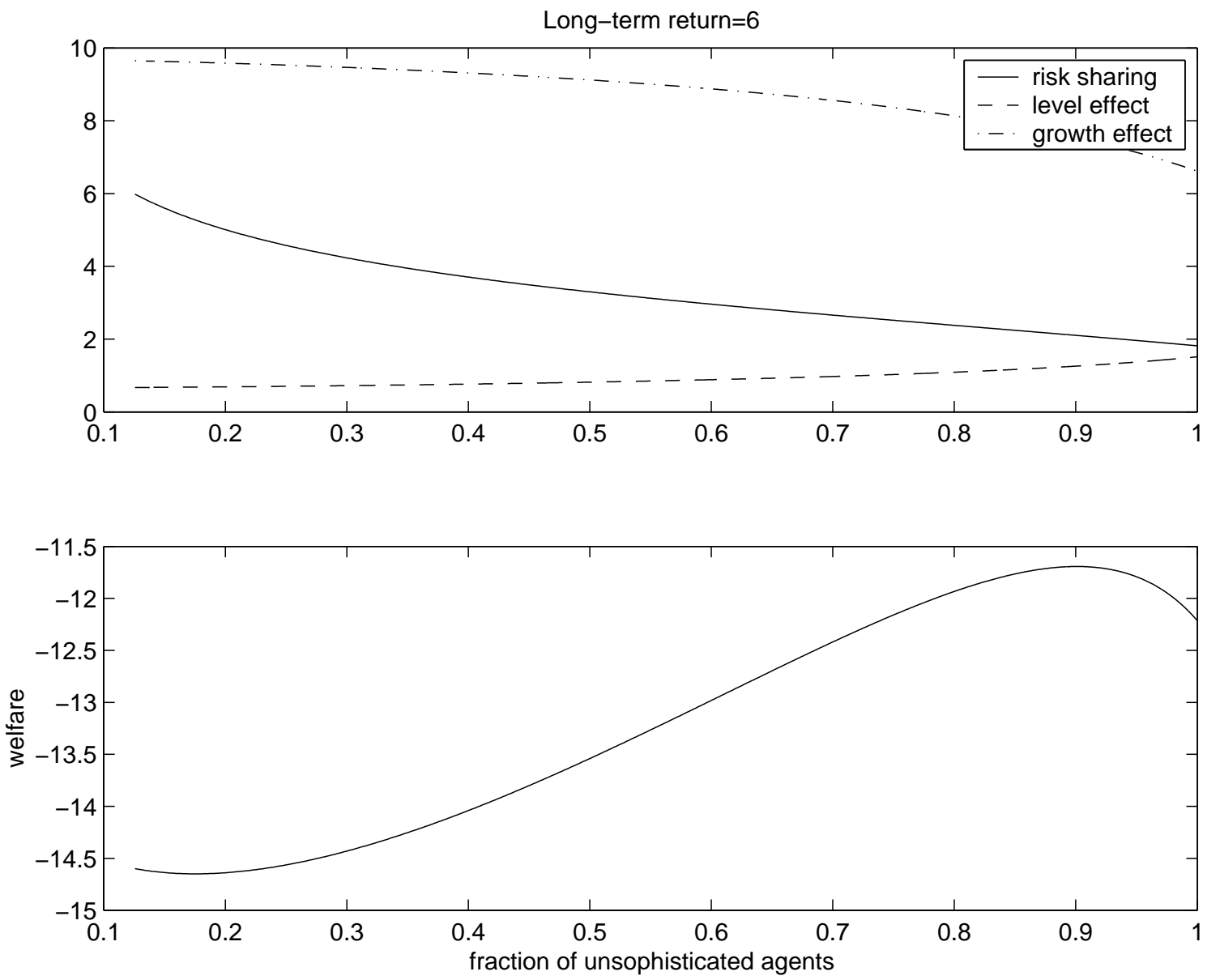

Figure 9. The case with a utility cost 

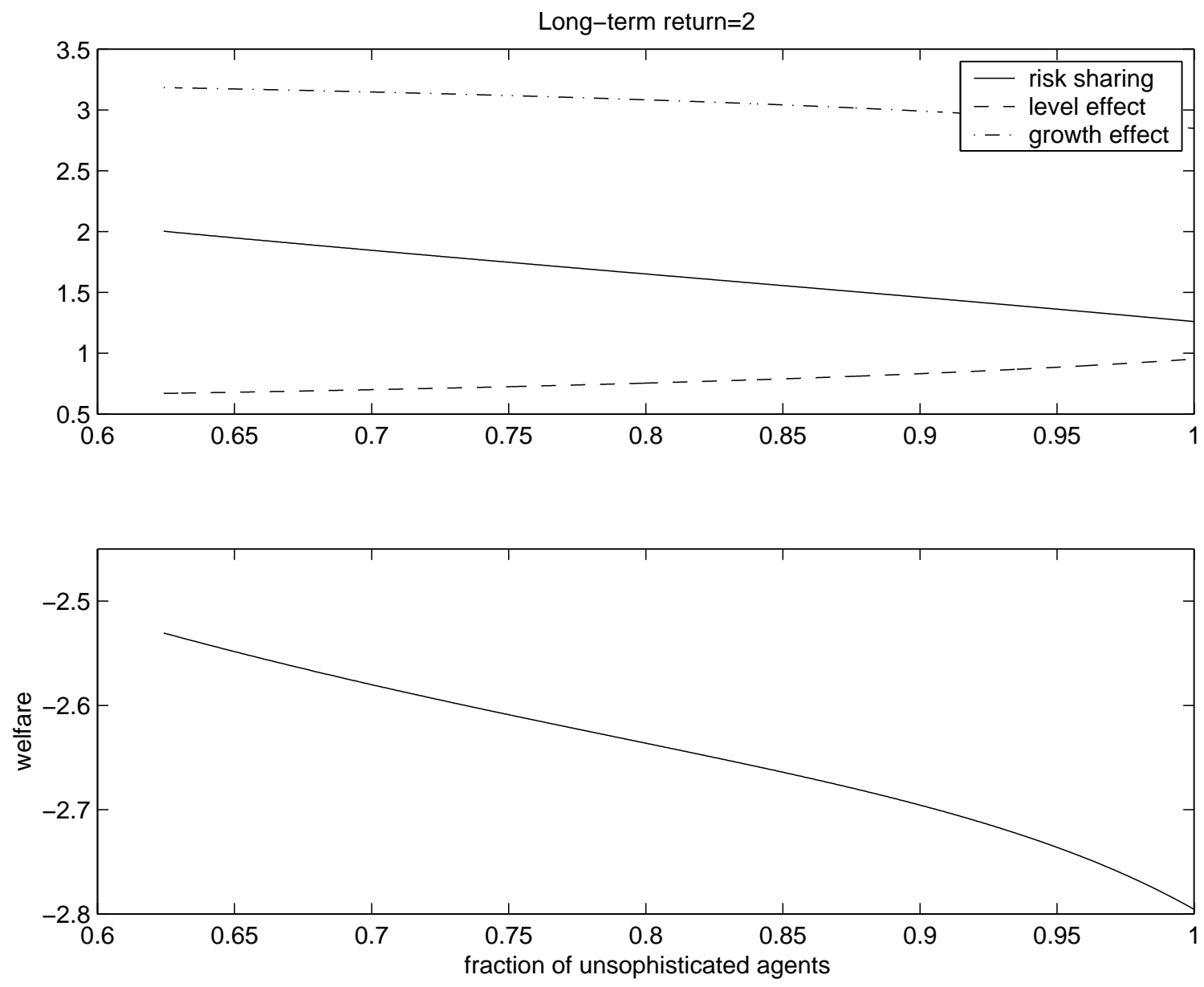

Figure 10. The case with a utility cost 

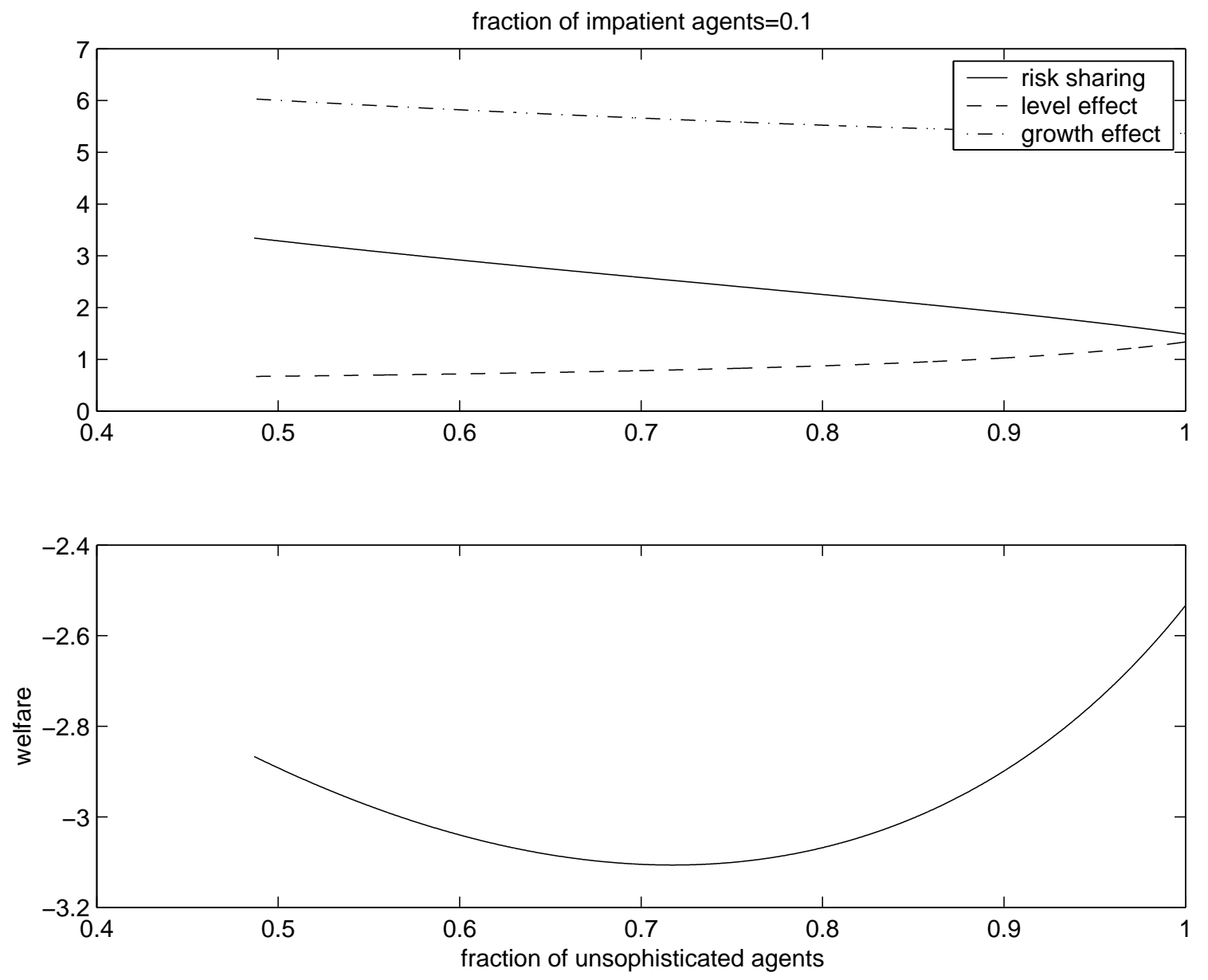

Figure 11. The case with a resource cost 

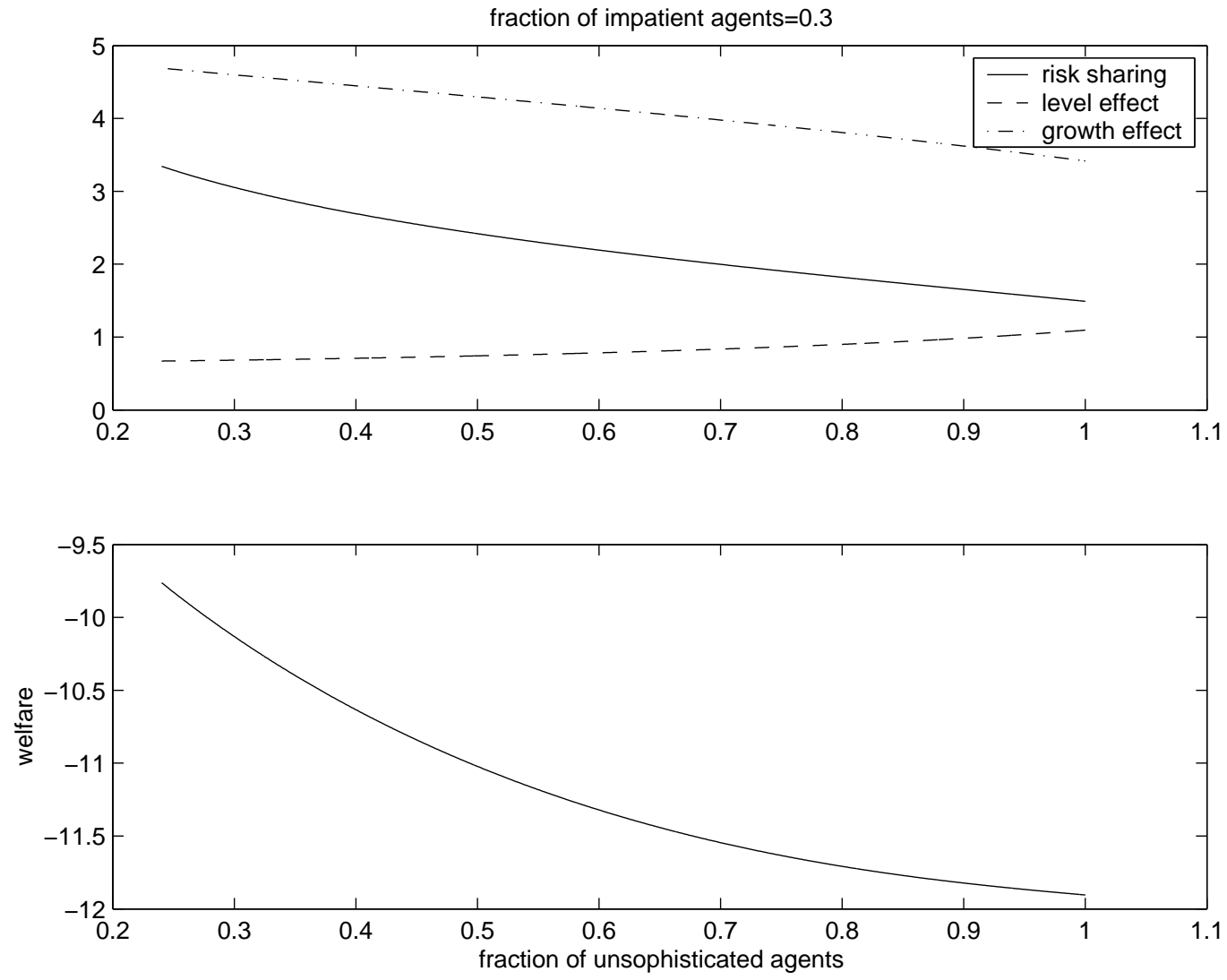

Figure 12. The case with a resource cost 

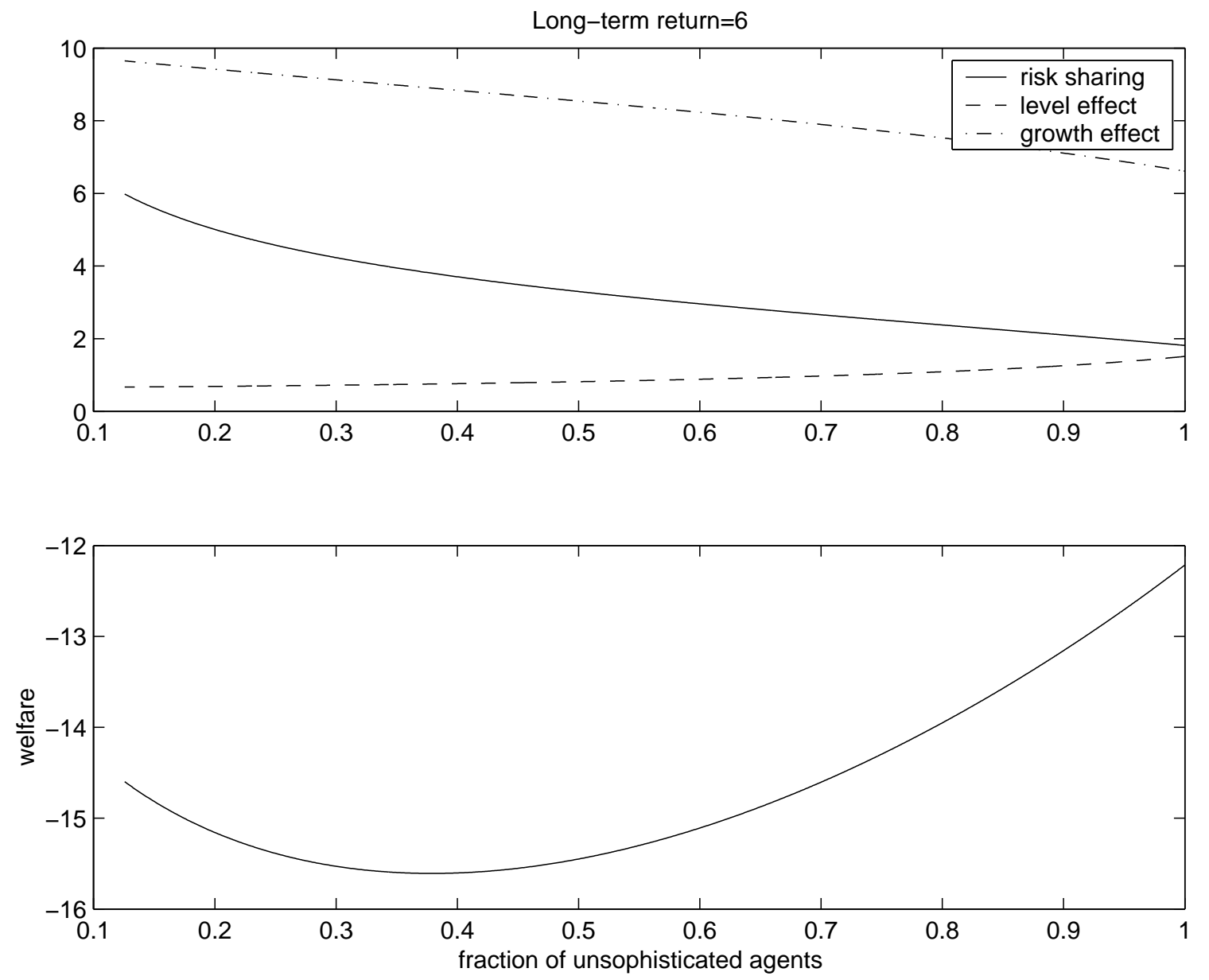

Figure 13. The case with a resource cost 

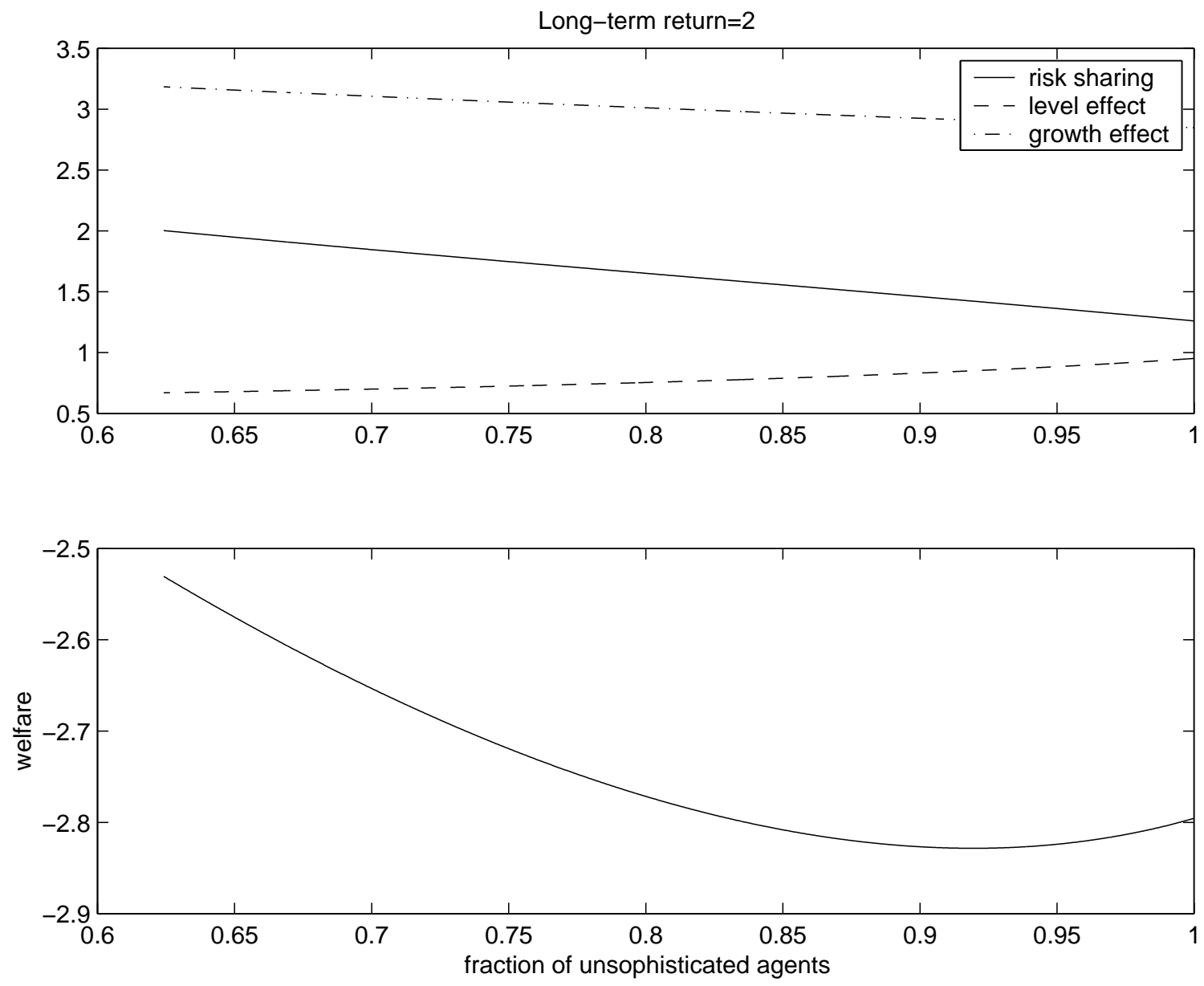

Figure 14. The case with a resource cost 